NBER WORKING PAPER SERIES

THE DOLLAR AS A SPECULATIVE BUBBLE:

A TALE OF FUNDAMENTALISTS

AND CHARTISTS

Jeffrey A. Frankel

Kenneth Froot

Working Paper No. 1854

NATIONAL BUREAU OF ECONOMIC RESEARCH

1050 Massachusetts Avenue

Cambridge, MA 02138

March 1986

The research reported here is part of the NBER's research program in International Studies. Any opinions expressed are those of the authors and not those of the National Bureau of Economic Research. 
NBBER Working Paper \#].854

March 1986

The Dollar as a Speculative Bubble:

A Tale of Fundamentalists and Chartists

\begin{abstract}
Several recent developments have inspired us to consider a non-standard model of the dollar as a speculative bubble without the constraint of fully rational expectations: (1) the dollar continued to rise in 1984 after real interest rate differentials and other fundamentals began moving the wrong way; (2) the results of market efficiency tests imply that the rationally expected rate of dollar depreciation has been less than the forward discount; (3) Krugman-Marris current account calculations suggest that the rationally expected rate of depreciation is greater than the forward discount; (4) survey data show an expected rate of depreciation that is also greater than the forward discount; (5) the hypothesis of a "safe-haven" shift into U.S. assets and a decrease in the U.S. risk premium, which would explain some of the foregoing, is contradicted by a decline in the differential between offshore interest rates (covered) and U.S. interest rates.

Our model features three classes of actors: fundamentalists, chartists and portfolio managers. Fundamentalists forecast a depreciation of the dollar based on an overshooting model that would be rational if there were no chartists. Chartists extrapolate recent trends based on an information set that includes no fundamentals. Portfolio managers take positions in the market, and thus determine the exchange rate, based on expectations that are a weighted average of the fundamentalists and chartists. The first stage of the dollar appreciation after 1980 is explained by increases in real interest differentials. The second stage is explained by the endogenous takeoff of a speculative bubble when the fundamentalists have mis-forecast for so long that they have lost credibility. In 1985, the dollar may have entered a third stage in which an ever-worsening current account deficit begins a reversal of the bubble.
\end{abstract}

Jeffrey A. Frankel

Department of Economics

University of California

Berkeley, CA 94720
Kenneth A. Froot

Department of Economics

University of California

Berkeley, CA 94720 


\title{
The Dollar as a Speculative Bubble: A Tale of
}

\section{Fundamentalists and Chartists}

\author{
Jeffrey A. Frankel
}

Kenneth A. Froot

University of California, Berkeley

\section{Introduction}

When the dollar began to appreciate in 1980, there was no shortage of economists who thought they could explain it on the basis of economic fundamentals. But as the appreciation continued, it became harder to explain. Especially after mid-1984, with fundamental variables moving in the wrong direction (money growth rates, short-term interest rates, long-term real interest rates, trade deficits and apparent risk factors), more economists began to consider seriously the possibility that the dollar was on a speculative bubble path.

As early as 1982, Dornbusch had applied the notion of stochastic rational bubbles to the case of the strong dollar. According to this theory, there is a probability at any point in time that the bubble will burst during the

Much of this research was conducted in the Fall of 1985 , while the authors were visiting at the International Monetary Fund and the Federal Reserve Board, respectively. We would like to thank Kethryn Dominguez of Yale University and Laura Knoy of the Institute for International Economics for generously providing survey data on exchange rate expectations (from Money Market Services, Inc., and the Economist Einancial Renort respectively) and John Calverl y and Barbara Bruer of American Express for providing similar data. We would also like to thenk the National Science Foundation under grant No. SES 8218300 and the Alfred P. Sloan Foundation for research support, and Tom Walter for research assistance. The views expressed are those of the authors, and do not represent any organiza-
tion. tion. 
subsequent period and the value of the currency will return to the equilibrium level determined by fundamentals. The differential in interest rates fully reflects and compensates for the possibility of the bubble bursting.

More recently it has been suggested that the dollar may in fact be on an irrational bubble path. Two influential papers, Marris (1985) and Krugman (1985), argue that the mounting U.S. indebtedness to foreigners represented by record current account deficits will eventually force the dollar down sharply, and that this prospective depreciation is not correctly reflected in the small forward discount or interest differential (either short-term or long-term). "It appears that the market has simply not done its arithmetic, and has failed to realize that its expectations about continued dollar strength are not feasible" (Krugman (1985), p. 40).1

Meanwhile, evidence has continued to accumulate that the forward discount is a biased predictor of the future spot rate. A favorite way of explaining away such apparent statistical rejections of rational expectations is to appeal to the sort of "peso problem" that might arise in a speculative bubble. But one of the present authors has presented calculations that tend to undermine the hypothesis that the dollar could have been on a single rational bubble from 1981 to 1985.2 The expected probability of collapse that investors have built in to the observed interest differential was high enough that it is very unlikely the dollar would have made it through four years without the bubble bursting, if that expectation was rational. This leaves the possibility of an irrational bubble where the true probability of collapse may be different from the expected probability that investors build in to the forward discount.

1 Kling (1985) also argues that the value of the dollar rests on rarket expectations that do not embody a return to steady state. Ten years earlier, McKinnon (1976) attributed exchange rate volatility to a "deficiency of stabilizing speculation" that is, an unwillingness of investors to take open positions based on fundamentals equilibrium, rather than to "high capital mobility with rational expectations" as the orthodoxy has it.

2 Frankel $(1885 a, b)$. 
In this paper we propose the outlines of a model of a speculative bubble that is not constrained by the assumption of rational expectations. The model features three classes of actors: fundamentalists, chartists and portfolio managers. None of the three acts utterly irrationally, in the sense that each performs the specific task assigned him in a reasonable, realistic way. Fundamentalists think of the exchange rate according to a model -. say, the Dornbusch overshooting model for the sake of concreteness--that would be exactly correct if there were no chartists in the world. Chartists do not have fundamentals such as the long-run equilibrium rate in their information set; instead they use autoregressive models--say, simple extrapolation for the sake of concreteness--that have only the time series of the exchange rate itself in the information set. Finally portfolio managers, the actors who actually buy and sell foreign assets, form their expectations as a weighted average of the predictions of the fundamentalists and chartists. The portfolio managers update the weights over time in a rational Bayesian manner, according to whether the fundamentalists or the chartists have recently been doing a better job of forecasting. Thus each of the three is acting rationally subject to certain constraints. Yet the model departs from the reigning orthodoxy in that the agents could do better, in expected value terms, if they knew the complete model. When the bubble takes off, agents are irrational in the sense that they learn about the model more slowly than they change it. Furthermore, the model may be unstable in the neighborhood of the fundamentals equilibrium, but stable around a value for the dollar that is far from that equilibrium.

This departure from orthodoxy is radical enough to call for some further motivation. As Franco Modigliani says, one does not want to abandon rational expectations except as a last resort. Section 2 discusses the apparent failure of models based on fundamentals, the apparent failure of the rational expecta- 
tions hypothesis, and the apparent failure of the models of a rational speculative bubble, to accord fully with simple empirical facts of the 1981-85 period. Section 3 elaborates on the distinction between chartists and fundamentalists, and offers some evidence from expectations survey data that respondents seem to form very short-term expectations more like chartists and more long-term expectations like fundamentalists. Section 4 describes the model in more detail and shows how it can work to explain the 1980-85 path of the dollar.

\section{What Is Wrong With Models Based on Fundamentals and Rational Bubbles?}

This is not the place to survey existing models of exchange rate determination. ${ }^{3}$ Nor are we going to argue that the empirical evidence shows the fundamentals models to be worthless. We actually believe with many others that the appreciation of the dollar, at least in its earlier stages, was explained relatively well by increases in real interest differentials, in turn attributable to shifts in the U.S. monetary/fiscal mix, as in the standard models that predate the $1980 \mathrm{~s}$ experience. (We consider below the more novel fundamentals hypothesis that the increase in the real interest differential and in the real value of the dollar were attributable to improved tax treatment of business and to "safe haven" motives.) Under a wide variety of measures of expected inflation, the real interest differential, both long-term and short-term, rose sharply after 1980. But by most measures the short-term real differential peaked in mid-1982, and by virtually all measures it declined after mid-1994, either short-term or longterm. Thus, as Dornbusch (1983) pointed out, the puzzle for models based on fundamentals is not why the dollar rose initially, but why it stayed so high so long:

3 Models of exchange rate determination developed in the 1970s are surveyed in Frankel (1983). In an infuential paper, Meese and Rogoff (1983) show that these models perform. very poorly out of sample. More recent developments, including the real interest differential calculations cited in the text, are covered in Frankel (1985b). 
"The [overshooting] model for the real interest rate does well in explaining that a rise in U.S. interest rates should lead to an appreciation of the real exchange rate. But it fails when it predicts that the real exchange rate should also be depreciating. That has not in fact been happening, and a theory is needed that will explain why the dollar - real or nominal - is both high and stuck."

The dollar began its long-awaited depreciation in March 1985. If that trend continues, then the period during which real interest rates and the dollar were clearly moving in opposite directions will have been confined to nine months or so, not sufficient grounds in itself for jettisoning the existing models. Nevertheless, the appreciation up through February 1985 was spectacular enough, and the value of the dollar remained high enough thereafter, to lead a number of economists to suggest the bubble hypothesis. Thus it is worthwhile to see whether the hypothesis can be formalized in a manner consistent with the empirical facts.

\subsection{Tests of Rational Expectations, and the Risk Premium in the Forward Market}

Both Krugman and Marris have mentioned as partial support for their claim that the foreign exchange market may not be rational the large econometric literature that statistically rejects the hypothesis that the forward discount (or equivalently, by covered interest parity, the interest differential) is an unbiased predictor of the future spot rate. The most common test in this literature is a regression of the ex post change in the spot exchange rate against the forward discount at the beginning of the period. Under the null hypothesis the coefficient should be unity. But most authors have rejected the null hypothesis, finding that the coefficient is much closer to zero, and some even finding that the coefficient is of the incorrect sign. Even if one does not wish to go along with the extreme form of the conclusion, that the forward market points in the wrong direction, the implication is nonetheless that one 
could expect to make money by betting against the forward discount whenever it is non-zero. 4

This forward market finding poses a puzzle in the context of the KrugmanMarris characterization of the dollar. It implies that as of 1985 for for that matter at any time over the last five years) the rationally expected rate of future dollar depreciation is less than the 3 percent a year implied in the forward discount. 5 The Krugman-Marris argument is that the rationally expected rate of future dollar depreciation would be much greater than the 3 percent a year implicit (against the mark) in the market. ${ }^{6}$ If we are to allow expectations to fail to be rational, we must somehow reconcile the two conflicting kinds of failure.

More discussion of the alleged bias in the forward exchange market is required. Most of the literature (for example the papers cited in footnote 4) does not interpret the finding as necessarily rejecting the hypothesis of rational expectations. Two other possible explanations are routinely offered: the existence of a risk premium, and the "peso problem." We believe that, while both factors can be very important in other contexts, neither explains the systematic prediction errors made by the forward market during the strong-dollar

4 Studies regressing against the forward discount include Tryon (1978), Levich (1980). Bilson (1981), Longworth (1981), Longworth, Boothe and Clinton (1883), Fama (1984) and Huang (1984). Cumby and obstfeld (1984) regressed against the interest differential and again found that for most exchange rates the coefficient was significantly iess than 1.0 and even less than zero. These findings are also consistent with those of Heese and Rogoff (1983) that the random walk predicts not only better than other mode's, but better than the forward discount as weli.

5 During the period June 1981 to March 1985 the 3- and 6-month forward markets have been significantly biased (underpredicting the value of the dollar) even unconditicnally. In other words, one could have made money by following the rule to be always long in doliars regardless what the forward discount was (Frankel and Froot (1985, 18-20)). Expectations survey data show the same unconditional bias. Their availability dictated the choice o: sample period.

${ }^{6}$ Krugman and Marris did not say that there is any reason to think that the dol:ar plunge would necessarily come in the next year; the focus is on the rarket's expected long-term rate of depreciation implicit in the long-term interest differential. We have no tests of unbiasedness going out a year or more. The problem is not the aisence of a forward market going out more than a year; we can always use the long-tern interest differential. The problem is rather that twelve years of floating-rate data would not offer enough independent observations. 
period. We consider the risk premium in the next two subsections, and the peso problem in the third one.

The first possible explanation is that the systematic component of the apparent prediction errors is really a risk premium separating the forward rate from investors' true expectations. It is a difficult argument either to refute or confirm, because expectations are not directly observable. More information is needed. The most appealing source of additional information is the theory of optimal portfolio diversification, which says that the risk premium, if that is what the systematic prediction errors are, should be related to such factors as the degree of investor risk aversion, the "outside" supplies of nominal assets denominated in various currencies, the variance-covariance matrix of exchange rates, and covariances with returns on other assets and opportunities. It seems plausible that a positive risk premium on dollars of this type explains some positive fraction of the 1985 forward discount (or interest differential) given the great increase in recent years in the supply of dollar assets as a share of the world portfolio, relative to the likely determinants of demand (i.e., given the record federal budget and current account deficits without likely corresponding movements in residents' minimum-variance portfolios). Unfortunately, the theory of optimal portfolio diversification, together with the standard estimates of the coefficient of relative risk-aversion being in the neighborhood of 2.0,? implies that the magnitude of the risk premium is on the order of only a few basis points. Unless the true coefficient of risk-aversion is much higher than is conventionally thought, the risk premium cannot explain more than a small fraction of the bias in the forward discount. 8

7 Friend and Blume (1875) estimate the coefficient of relative risk-aversion to be in the neighborhood of two in the context of investors' portfolio behavior. Stern (1977) provides a survey of estimates in other contexts, most also in the neighborhood of two.

$\theta$ If the supply of dollar assets happens to correspond to the share in the minimumvariance portfolio, then the risk premium is zero. As of 1984 the ratio oi outstanding U.S. government debt to a total portfolio of seven countries' debt and twenty countries' equities was (in billions of doliars) about $1,577 /(2,465+2,941)=0.29$. Even if inis share has gone 
The conclusion that international substitutability is very high, and thus that the risk premium is very small, depends entirely on the optimal portfolio argument. The hypothesis that investors diversify their portfolios optimally has not itself held up well to statistical tests. ${ }^{9}$

If one is prepared to abandon the portfolio optimization hypothesis, there are few alternative sources of information to help isolate the risk premium out of the prediction errors made by the forward discount. One promising possibility is the surveys of market participants' exchange rate expectations conducted by the Economist's Financial Report and the American Express Bank Review. ${ }^{10}$ In Frankel and Froot (1985) we showed that those data for the 198185 period reflect a considerably greater expectation of dollar depreciation than do the forward discount or interest differential. (Some of the relevant statistics are reported in Table 3 below.) We repeated standard tests of unbiasedness in expected depreciation and found even more significant rejections when the survey data, which must be free from any risk premium, are used than when the forward discount is used. One would have persistently made money in the $1980 \mathrm{~s}$ either by following the rule "buy and hold dollars" (unconditional bias) or by following the rule "always bet against the forward discount" (the same conditional bias found in the earlier studies cited in footnote 4). A second paper, Froot $(1985,21-23)$, shows that the rejection of rational expectations holds up even if one allows for measurement error in the survey data (provided it is up by .10, through some combination of deficits and dollar appreciation, the implication is that the risk premium paid on dollar assets has gone up by only about 0.20 percent per annum or 20 basis points. Thus the risk premium accounts for very little of a 300 basis point interest differential. Frankel $(1985 a, 211-217)$ presents these numbers, develops the a priori argument that the risk premium must be small, and gives other references. The essence of the argument is originally due to Krugman (1981).

8 Frankel and Engel (1984) reject the international optimization hypothesis in a meanvariance framework. Hodrick and Srivastava (1984) do so in a more general intertemporal framework.

10 The Economist survey covers 13 leading international banks and has been conducted six times a year since 1981. The American Express survey covers 250 to 300 centra! bankers, private bankers, corporate treasurers and economists, and has been conducted more irregularly since 1976. 
random): one can reject the hypothesis that expectations are rational and that the apparent bias in the survey numbers is entirely due to measurement error. In addition, Froot tests the hypothesis that no information about the risk premium is revealed in regressions of the ex post change in the spot rate on the forward discount. This hypothesis cannot be rejected, suggesting that the risk premium does not help explain why changes in the forward discount mispredict future changes in the spot rate.

\subsection{A Test of the Safe-Haven Hypothesis}

If the survey numbers are taken seriously as measuring investors' rate of expected depreciation, they imply a large negative risk premium paid on dollar assets during the 1981-85 period (a sharp decline from the near-zero risk premium in the 1970s). This is very different from either the positive risk premium implied by standard tests of bias in the forward discount or the near-zero risk premium implied by portfolio optimization. Is a negative risk premium plausible nevertheless? Standard portfolio considerations would suggest not. The exchange risk premium in theory should depend on such variables as asset supplies and on return variances and covariances. The large U.S. government budget deficit and current account deficits mean that asset supplies should currently be driving the dollar risk premium up, not down. One could posit an increase in the perceived riskiness of European currencies relative to the dollar, attributable to for example to an increase in uncertainty regarding European monetary policy relative to U.S. monetary policy. But in that case it would be diffecult to explain the increase in the U.S. interest differential after 1980; by itself a shift in demand toward U.S. assets due to uncertainty should have driven U.S. interest rates down. ${ }^{11}$

11 Similary an increase in U.S. monetary uncertainty could expian higher U.S. Interest rates, but not the appreciation of the dollar. On these points, see Branson (1985) and The Council of Economic Advisers (1984, pp. 54-55) 
There is one explanation that has been seriously proposed for the dollar appreciation that is consistent with both a fall in the risk premium on dollars and an increase in the interest differential, in other words, consistent with the expected rate of depreciation increasing even more than the interest differential. That is the so-called "safe haven" explanation: an exogenous shift in demand toward U.S. assets due to perceptions of reduced country risk in the United States relative to abroad. According to this theory, risk has declined in the United States because of an improved business climate, in particular improved tax treatment for investment after 1981, which also explains the increase in U.S. real interest rates via an alleged investment boom. ${ }^{12}$ Risk has increased in the rest of the world, not just because of debt problems in Latin America (which would alone not be relevant for the exchange rate or return differentials between the United States and Europe) but also because of political or country risk in Europe. Dooley and Isard (1985), for example, speak of a perceived threat of penalties on capital in Europe. "where the term 'penalty' is loosely defined to include formal taxation, the postponement of interest and principal payments, confiscation, destruction of property, and so forth."

We here propose a simple test be used to evaluate the safe haven hypothesis: a comparison of interest rates paid on securities that are physically located offshore, but that are denominated in dollars or otherwise covered on the forward exchange market to get around the problem of exchange risk, with interest rates paid on securities in the United States. That is, we are testing international closed, or covered, interest parity, not uncovered interest

12 One widely cited piece of evidence against the safe haven hypothesis is that the increase in U.S. real interest rates was accompanied by a lower investment rate averaged over the 1981-85 period, not a higher one. (See, for example, Friedman (1985) or Frankei (1985a).) However others dispute this calculation; see Blanchard and Summers (1984). Another piece of evidence against the safe haven hypothesis is that the correlation between U.S. stock market price changes and those abroad (Germany or Japan) has been positive; Obstfeld (1985) argues that if portfolio demands had exogenously shified irom foreign assets to U.S. assets, the U.S. Stoc' market boom should have been accompanied by a stock
market decline abroad. 
parity. Tests of the offshore-onshore differential have been frequently employed to illustrate a number of points about the existence of capital controls or country risk: a negative differential for Germany until 1974 showed that capital controls discouraged capital inflow (Dooley and Isard (1980)); a positive differential for the United Kingdom until 1979 showed that capital controls discouraged outflow; positive differentials for France and Italy show that controls still discourage outflow (e.g., Giavazzi and Pagano (1985), Claassen and Wyplosz (1982)); a negative differential for Japan until 1979 showed that controls discouraged inflow (Otani and Tiwari (1981); Ito (1984) and Frankel (1984)); and, but for the foregoing exceptions, the generally small magnitude of differentials shows that capital mobility is very high among the major industrialized countries (e.g., Frenkel and Levich (1975), McCormick (1979), Boothe et al. (1985)).13

Table 1 reports mean daily differentials between of̂shore interest rates (covered) and domestic U.S. interest rates, for seven different pairs of securities. Remarkably, there was a relatively substantial positive differential in almost all cases, until recently, regardless whether one observes the offshore interest rate in the Euromarket, in the domestic U.K. market, or in the domestic German market.14 From 1979 to 1982, the Euromarket rates exceeded the U.S. interbank rate by an average of about 100 basis points. A number of studies have noted that the Eurodollar rate does not move perfectly with the U.S. interbank or CD rate (Hartman (1983), Kreicher (1982)). They attribute the differential primarily to the fact that U.S. banks face reserve requirements

\footnotetext{
13 "Small" might be defined as less than 50 basis points, to anlow for differences in default risk and tax treatment attaching to the particular security, as well as inevitable minor differences in timing.

14 In 1878 the differential between the domestic U.K. and domestic U.S. interest rate is negative (columns 4 or 5 in Table 1). This is because of the above-mentioned U.K.-capial controls that were removed in 1979 , as is evident from the differential between the Europound interest rate and domestic U.K. rates (column 2 or 3 in Table 2).
} 


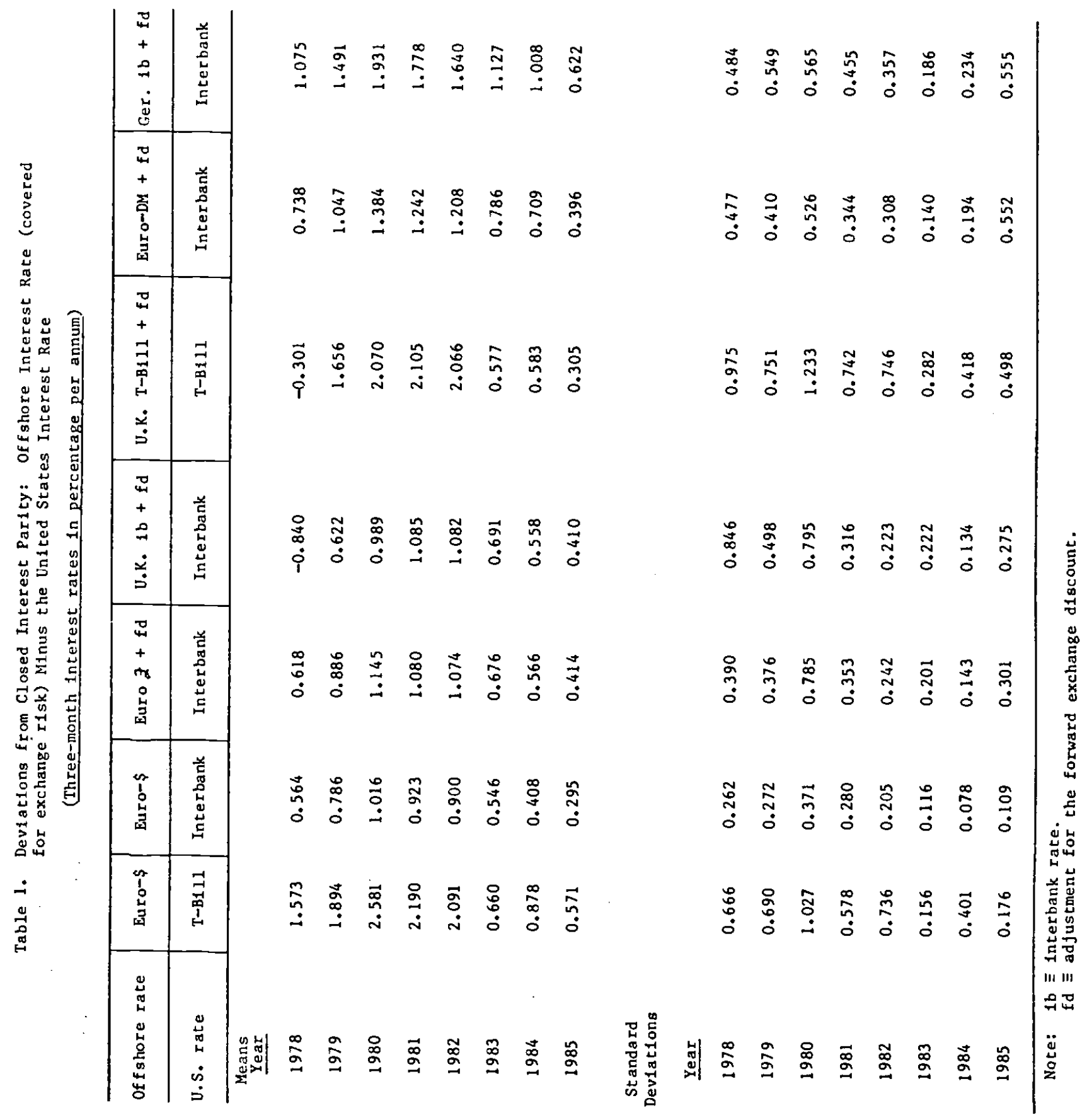


Table 2. Deviations from Interest Parity Within Jurisdictions

(Three-month interest rates in percentage per annum)

\begin{tabular}{l|c|c|c|c|c}
\hline & Euro $\$-f d$ & Euro $£$ & Euro $£$ & Euro \$ - fd & Euro DM \\
\hline & Euro $£$ & U.K. interbank & U.K. T-bi $1 i^{*}$ & Euro DM & Ge. interbank \\
\hline
\end{tabular}

Means

Year

$\begin{array}{llllll}1978 & -0.066 & 1.432 & 1.895 & -0.187 & -0.335 \\ 1979 & -0.103 & 0.289 & 0.363 & -0.220 & -0.444 \\ 1980 & -0.123 & 0.156 & 0.658 & -0.373 & -0.549 \\ 1981 & -0.161 & -0.004 & 0.228 & -0.319 & -0.525 \\ 1982 & -0.179 & 0.003 & 0.207 & -0.311 & -0.431 \\ 1983 & -0.131 & -0.010 & 0.217 & -0.239 & -0.341 \\ 1984 & -0.158 & 0.009 & 0.451 & -0.300 & -0.296 \\ 1985 & -0.121 & 0.008 & 0.393 & -0.100 & -0.222\end{array}$

Stand ard

Deviations

Year

$\begin{array}{llllll}1978 & 0.280 & 0.866 & 0.822 & 0.350 & 0.175 \\ 1979 & 0.272 & 0.288 & 0.466 & 0.408 & 0.253 \\ 1980 & 0.719 & 0.335 & 0.605 & 0.376 & 0.292 \\ 1981 & 0.286 & 0.250 & 0.470 & 0.250 & 0.317 \\ 1982 & 0.214 & 0.188 & 0.300 & 0.270 & 0.168 \\ 1983 & 0.179 & 0.143 & 0.240 & 0.088 & 0.113 \\ 1984 & 0.143 & 0.125 & 0.233 & 0.173 & 0.100 \\ 1985 & 0.285 & 0.119 & 0.418 & 0.552 & 0.094\end{array}$


against domestic deposits but not against Eurodeposits, so they are willing to pay a higher interest rate to depositors offshore. But the differential has been mostly swept under the rug in more general studies of covered interest parity.

Even those who have studied the Eurodollar-U.S. interbank differential treat it as a peculiarity of that particular market. This would make sense only if, on the one hand, the U.S. interbank rate were depressed below other U.S.interest rates (by U.S. reserve requirements) or if, on the other hand, Eurocurrency interest rates were raised above domestic European interest rates (either by analogous reserve requirements in European countries or by perceived default risk in the Euromarket). But neither of these effects seems to hold. Table 2 shows small spreads between the Eurodollar rate and the Europound or Euromark rates (covered) or between them and the domestic U.K. and German interest rates. Indeed, Table 1 shows that the spread between covered pound or mark interest rates and domestic U.S. rates is even higher, and comes down even more after 1982, when Treasury bill rates are used as when banking rates are used. This finding contradicts the hypothesis that U.S. reserve requirements are the only factor driving a wedge between the Euromarket and the U.S. interbank market and that more direct arbitrage through other means works to reduce that wedge.

Why were foreigners and U.S. residents buying U.S. Treasury bills in 19791982 when they paid about 2 percent less than U.K. Treasury bills? The obvious response is that U.S. securities were preferred for safe-haven reasons. But since the differential predates the appreciation of the dollar, there is some difficulty in associating the two. This is particularly true after 1982, when the differential declines sharply. By 1985, when the dollar had appreciated much further, the Eurodollar rate was only 30 basis points above the domestic U.S. interbank interest rate, in the same range as the differentials for the pound, 
mark, yen, Canadian dollar, and Swiss franc. Chart 1 shows a comparison of the London Interbank Offer Rate (LIBOR) with a domestic U.S. CD rate, adjusted for reserve requirements. The differential, which was clearly positive in the early 1980s, peaked during the Mexican debt crisis in August 1982, and has declined steadily ever since, currently to about zero. The evidence thus suggests that the United States was perceived as increasingly risky after 1982. The story based on safe-haven fundamentals does not explain the continued appreciation of the dollar from 1982 to February 1985 any better than the story based on real interest fundamentals. The field would appear to be open to bubble theories.

\subsection{Rational Speculative Bubbles and the "Peso Problem"}

The possibility of speculative bubbles leads to the second explanation, besides the risk premium, that is often given for the econometric findings of biasedness in the forward exchange market: the peso problem. The standard tests presume that the error term, the difference between expected depreciation and the ex post realization, is distributed normally and independently over time.But if there is a small probability of a big decline in the value of the currency, the distributional assumption will not be met, the estimated standard errors will be incorrect, and an apparent rejection of unbiasedness may be spurious. ${ }^{15}$ This problem is thought to be relevant for pegged currencies like the Mexican peso up until 1976, and normally less relevant for floating currencies. But if the dollar has been on a single speculative bubble path for four years, there could well be a small probability of a large decline in the form of a bursting of the bubble. It has been suggested that the forward discount may properly reflect that possibility, and that tests find a bias only because the

15 Evans (1985) avoids this problem by employing a nonparametric sign test of tne forward rate prediction errors. 


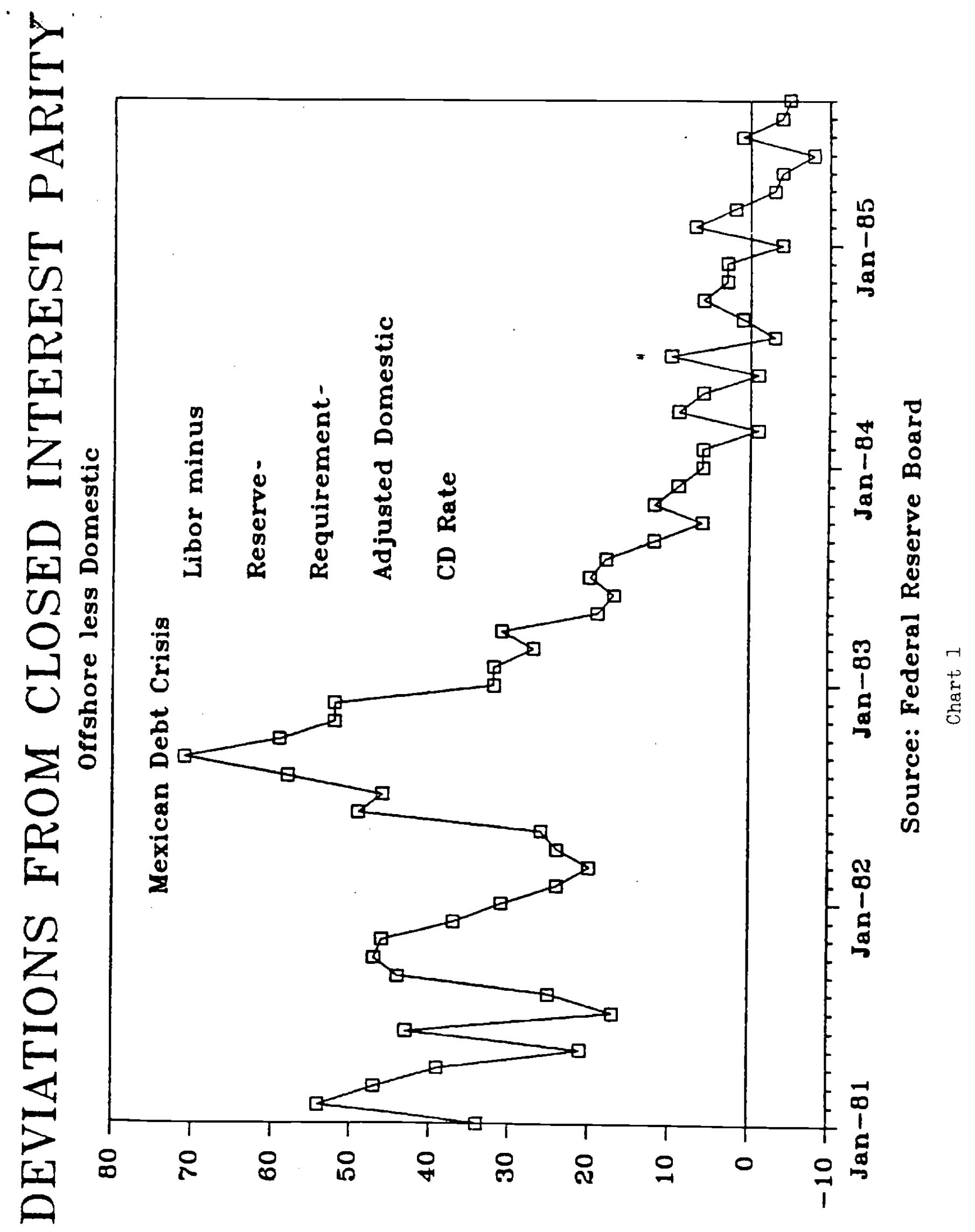

s7ulod siseg 
event happens not to have occurred in the sample.

Calculations in Frankel (1985a, b) tend to undermine the hypothesis that the forward discount during the period 1981-85 has reflected rational expectations of a small probability of a large decline in the value of the dollar. Under the hypothesis that the bursting of the bubble would reverse half of the real appreciation of the dollar against the mark that has taken place since the 1970s, a 3 percent forward discount in March 1985 implied a 2.8 percent perceived probability of collapse during that month. One can multiply out the implied probabilities of non-collapse since January 1981, with no distributional assumptions needed, to find that the chance that such a bubble would have persisted for four years without bursting is only 3 percent. Thus the peso problem does not "get the forward exchange market off the hook." The period during which the forward discount was positive with no realized depreciation simply went on too long for the rational expectations hypothesis to emerge intact.

\section{Fundamentalists and Chartists}

We can gather the conclusions reached so far into five propositions, each with elements of paradox.

(1) The dollar continued to rise even after all fundamentals (the interest differential, current account, etc.) apparently began moving the wrong way. The only explanation left would seem to be, almost tautologically, that investors were responding to a rising expected rate of change in the value of the dollar. In other words, the dollar was on a bubble path.

(2) Evidence suggests that the investor-expected rate of depreciation reflected in the forward discount is not equal to the rationally-expected rate of depreciation. The failure of a fall in the dollar to materialize in four years implies that the rationally-expected rate of depreciation has been less than the 
From

"Six Possible Meanings of 'Overvaluation': The 1981-85 Dollar"

Essays in International Finance, No. 159

December 1985

Princeton University

TABLE A-1

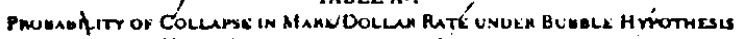

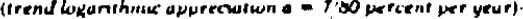

\begin{tabular}{|c|c|c|c|c|c|c|c|}
\hline \multirow[b]{2}{*}{ Monsh } & \multirow[b]{2}{*}{$\begin{array}{c}\text { Nomino(dporn } \\
\text { ciation of } \\
\text { Dullur } \\
(-1.3) \\
19.3 .79=0\end{array}$} & \multirow[b]{2}{*}{ 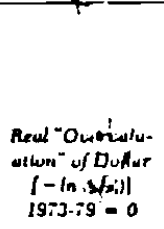 } & \multirow[b]{2}{*}{$\begin{array}{l}\text { Foruverd } \\
\text { Diwcunet } \\
\text { (FO) }\end{array}$} & \multicolumn{2}{|c|}{ 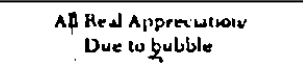 } & \multicolumn{2}{|c|}{$\begin{array}{l}\text { Haلs Reprecuston } \\
\text { Due to Bubble }\end{array}$} \\
\hline & & & & $\begin{array}{c}\text { Probuluitity } \\
\text { of Collubze } \\
\text { (D) }\end{array}$ & 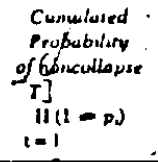 & $\begin{array}{l}\text { Probubulint } \\
\text { of Collunsis } \\
\text { (0) }\end{array}$ & 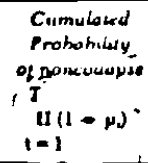 \\
\hline$j=n 81$ & -13.048 & 8.619 & 1006 & 0.164 & 0.83 & 0.314 & 0.69 \\
\hline Feb bl & -6.100 & 15.17 & 5.75 & 0.071 & $0 . \pi$ & 0.137 & 0.59 \\
\hline I & -8.26 & 13.69 & 2.64 & 0.001 & 0.73 & 0.117 & 0.52 \\
\hline Apr 81 & -5.69 & 16.2 .1 & 3.85 & 0 ust & 0.68 & 0.110 & $0 .+6$ \\
\hline $\begin{array}{lll} & 1\end{array}$ & 0.13 & 22.51 & 7.04 & 0.453 & 0.65 & 0.14 & 0.42 \\
\hline June HI & S. in & 25.61 & 5.45 & 0.042 & 0.62 & $0 . \infty 2$ & 0.35 \\
\hline Julkl & 6.52 & 29.67 & 7.14 & 0.041 & 0.50 & $0.0 \mathrm{su}$ & 0.35 \\
\hline Aus $x 1$ & טי.6 & 32.64 & 6.79 & 0.036 & 0.57 & 0.072 & 0.37 \\
\hline Sep XI & 2.75 & 27.04 & 5.12 & $0.03 y$ & 0.53 & 0.076 & 0.30 \\
\hline Oetrl & -1.67 & 22. 43 & +69 & 0.045 & 0.35 & 0.000 & 0.28 \\
\hline Nur 81 & -2.81 & 8109 & 278 & 0.041 & 0.50 & 0.079 & 0.23 \\
\hline Decri & -1.32 & 22.56 & 2.33 & 0.036 & 0.19 & 0.071 & 0.24 \\
\hline$J \ln 82$ & 0.14 & 27.64 & 3.79 & 0.040 & 0.17 & $0.0 \pi$ & 0.22 \\
\hline Feb 42 & 3.34 & 26.67 & 5.32 & 0.040 & $0 .+5$ & 0.078 & $0.21)$ \\
\hline Nas b2 & 3.92 & 27.32 & 5.83 & $0.0+1$ & $0+3$ & 0.059 & 0.18 \\
\hline Apr 62 & 4.71 & 28.27 & 6.34 & 0.01 & $0 .+1$ & 0.460 & 0.17 \\
\hline Mlaybz & 0.97 & 24.77 & 6.57 & 0.047 & 0.39 & 0.072 & 0.15 \\
\hline June 82 & 5.96 & 2988 & 6.38 & 0.039 & 0.35 & 0.096 & 0.14 \\
\hline Jul 82 & $7 .+3$ & 31.76 & 5.24 & 0.034 & 0.37 & 0066 & 0.13 \\
\hline Aug 82 & 0.02 & 32.61 & 2.61 & 0.026 & 0.36 & 0.051 & 0.13 \\
\hline Sep 82 & 9.02 & 33. 43 & 3.81 & 0.025 & 0.35 & 0.056 & 0.12 \\
\hline$\alpha \cdot k 2$ & 10.06 & .34 .35 & 3.58 & 0.027 & 0.34 & 0.053 & 0.11 \\
\hline Nov 12 & 11.14 & 35.00 & 2.89 & 0.025 & 0.33 & 0.049 & 0.11 \\
\hline Dex $\times 2$ & 5.59 & 28.7 & 3.32 & 0.032 & 0.32 & 0.062 & 0.10 \\
\hline $\operatorname{Jen} 80$ & 1.32 & 27. 40 & 3.78 & 0.024 & 0.31 & 0.067 & 0.00 \\
\hline Feh D. & 6.00 & 23.99 & 3.36 & 0.001 & 0.30 & 0.061 & 0.00 \\
\hline$M+283$ & 5.16 & 25.33 & 1. 49 & 0.005 & 0.29 & 0.069 & 0.08 \\
\hline A jr 83 & 6.4 & 30.01 & 1.61 & 0.024 & $0.2 x$ & 0.066 & 0.08 \\
\hline Nizy 83 & 7.51 & $31 .+1$ & 3.99 & 0.001 & 0.27 & $0.0 \times 0$ & 0.07 \\
\hline Jun 83 & 10.81 & 34.69 & +61 & 0.029 & 0.26 & 0.057 & 0.07 \\
\hline jul 103 & $12+2$ & 36.37 & 5.31 & 0.030 & 0.25 & 0.058 & 0.06 \\
\hline A US 85 & 15.64 & 39.57 & 5.10 & 0.027 & 0.25 & 0.053 & 0.06 \\
\hline$S_{e p} \times 3$ & 15.37 & 39.56 & +27 & 0.025 & $-\quad 0.24$ & 0.049 & 0.06 \\
\hline Ost 13 & 12.91 & $3 \div .32$ & $+.2 t$ & 0.026 & 0.23 & 0.052 & 0.05 \\
\hline Nor $8 \mathrm{~J}$ & 15.4 & +0.35 & 3.92 & 0.024 & 0.23 & 00017 & 0.05 \\
\hline Dec: 103 & 18.35 & 12.66 & 1.00 & 0.023 & 0.22 & 0.045 & 0.05 \\
\hline J & 2060 & 45.05 & 1.10 & 0.022 & 0.2 .2 & 0.043 & 0.05 \\
\hline Feb or & 16.64 & 11.21 & 1.09 & 0.024 & 0.21 & 0.047 & 0.05 \\
\hline Mlar $M t$ & 12.68 & $37.4 t$ & +40 & 0.025 & 0.21 & 0.055 & 004 \\
\hline Apr \&4 & 1451 & 39.58 & 5.32 & 0.027 & 0.30 & 0.054 & 0.04 \\
\hline Nay bat & 18.78 & 13. 69 & 5.63 & 0 O25 & $0 . \pm 0$ & 0050 & 0.04 \\
\hline Jurle ba & 1800 & $\$ 3.31$ & 5.45 & 0 0:6 & 0.19 & 0.051 & 0.04 \\
\hline Jul Bu & 21.92 & +7.04 & 0.4 & 0.025 & 0.19 & 0.045 & 003 \\
\hline A IIR $\$$ & 23.27 & +9.56 & $6.5 y$ & 00.21 & 0.18 & O U & 0.03 \\
\hline Sepind & $28 \mathrm{w}$ & 54.75 & 6.28 & 0.021 & 018 & 0.042 & $0 \omega 3$ \\
\hline O.tW & $29+0$ & 35.64 & 5.15 & 0.019 & 0.17 & 11 & u.u \\
\hline Novis & 2687 & 53.14 & 3.4 & 0.015 & 0.17 & 0436 & 0.03 \\
\hline Dec kt & 30.50 & 56.72 & 3.22 & 0.016 & 0.17 & 0.072 & 0.00 \\
\hline Jas ill As & 72.63 & $5 x+2$ & 2.177 & 0.015 & $0: 7$ & 0.032 & 0.03 \\
\hline Feb ks & 3661 & $62+10$ & 2.62 & OUIt & 0.16 & 0 U27 & $0 . w$ \\
\hline 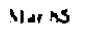 & 3860 & 6439 & 307 & 0.01t & บ. 16 & Oע. & 0.00 \\
\hline
\end{tabular}


forward discount.

(3) On the other hand, Krugman-Marris current account calculations suggest that the rationally-expected rate of depreciation is greater than the current forward discount.

(4) The survey data show that the respondents have since 1981 indeed held an expected rate of depreciation substantially greater than the forward discount. But interpreting their responses as true investor expectations, and interpreting the excess over the forward premium as a negative risk premium, raises several problems. First, if investors seriously expected the dollar to depreciate so fast, why did they buy dollars? Second, the theory of exchange risk says that the risk premium should generally be small and, for the dollar in the 1980 s, that it probably has moved in the positive direction.

(5) In the safe-haven theory, a perceived shift in country risk rather than exchange risk might seem to explain many of the foregoing paradoxes. However, the covered differential between European and U.S. interest rates actually fell after 1982 suggesting that perceptions of country risk, if anything, shifted against the United States.

The model of fundamentalists and chartists that we are proposing has been designed to reconcile these conflicting conclusions. To begin with, we hypothesize that the views represented in the American Express and Economist 6-month surveys are primarily fundamentalist, like the views of Krugman and Marris (and most other economists). But it may be wrong to assume that investors' expectations are necessarily the ones reported in the 6-month surveys or that they are even homogeneous (as most of our models do). Expectations are heterogeneous. Our model suggests that the market gives heavy weight to the chartists, whose expected rate of change in the value of the dollar has been on average much closer to zero, perhaps even positive. Paradox (4) is answered if 
fundamentalists' expectations are not the only ones determining positions that investors take in the market.

The increasing dollar overvaluation after the interest differential peaked in 1982 would be explained by a falling market-expected rate of future depreciation, with no necessary basis in fundamentals. The market-expected rate of depreciation declined over time, not necessarily because of any change in the expectations held by chartists or fundamentalists, but rather because of a shift in the weights assigned to the two by the portfolio managers, who are the agents who take positions in the market and determine the exchange rate. They gradually put less and less weight on the big-depreciation forecasts of the fundamentalists, as these forecasts continue to be proven false, and more and more weight on the chartists.

Before we proceed to show how such a model works, we offer one piece of evidence that there is not a single homogeneous expected rate of depreciation reflected in the survey data: the very short-term expectations (one-week and two-week) reported in a third survey of market participants, by Money Market Services, Inc., behave very differently from the medium-term expectations $(3,6$, or 12 month) reported in any of the three surveys. ${ }^{16}$

Table 3 shows expected depreciation (from all three surveys) at a variety of time horizons. Perhaps most striking is a large fall in the standard deviation of the mean as the forecast horizon increases. At the short end of the spectrum, none of the means from the one-week forecasts is significantly different from zero at the one percent level, and the standard deviations are large, ranging from 4.2 percent to 9.1 percent. ${ }^{17}$ At the other extreme, the one-year forecast

\footnotetext{
16 For a more extensive analysis of this survey data set, see Dominguez (1986).

17 For all currencies combined, the standard deviation of the means treat the value of each currency against the dollar as independent. To the extent that all the forecasts contain a common dollar component, these aggregate standard deviations are biased downward, so that the corresponding t statistics are overstated.
} 


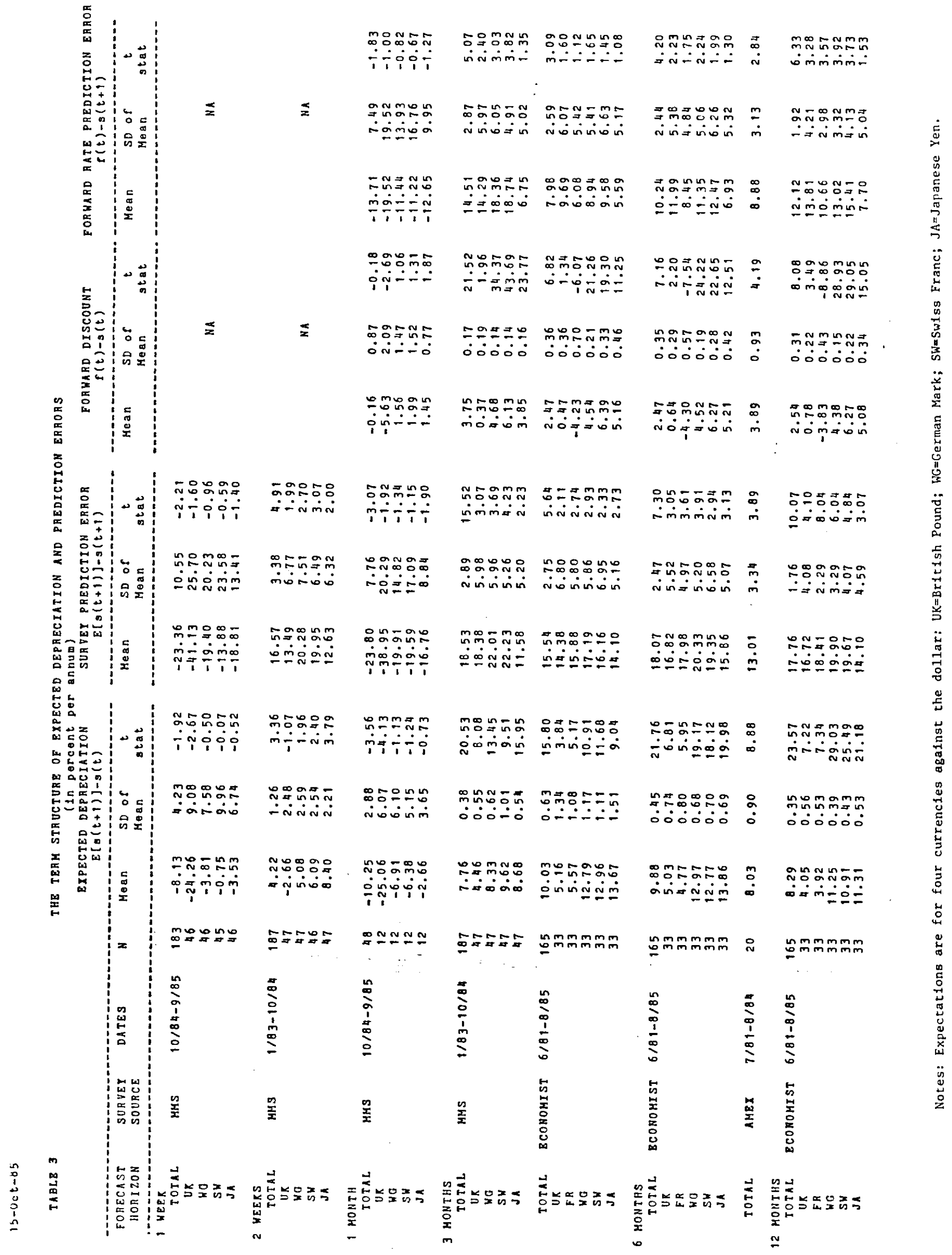


horizon, all of the means are highly significant with $t$ statistics approaching 30 , and the standard deviations are below 0.6 percent. The intermediate horizons conform to this pattern of decline.

A second striking fact is that the one-week and one-month surveys, which were conducted only for $10 / 84$ to $9 / 85$, indicate that respondents on average expected the dollar to appreciate often at a rapid annual rate. During the comparable period for which 12 month forecasts are available (1/85-4/85). expected depreciation was still large and positive at 7.32 percent as well as significant $(t=8.29)$.

These two facts suggest that there are far more consistent views about the value of the dollar in the longer run than in the shorter run; while short-run expectations may predict appreciation or depreciation at different times, longer-run forecasts consistently call for substantial depreciation. It is as if there are actually two models of the dollar operating, one at each end of the spectrum, and a blend in between. The fundamentalist model, for which we specify a Dornbusch overshooting model, can be identified with the longer-run expectations. The chartist model, a simple ARIMA forecasting equation such as a random walk, might be identified with the shorter run. Under this view, respondents use some weighted average of the two models in formulating their expectations for the value of the dollar at a given future date, with the weights depending on how far off that date is.

These results suggest an alternative interpretation of how chartist and fundamentalist views are aggregated in the marketplace, an aggregation that takes place without the benefit of portfolio managers. It is possible that the chartists are simply people who tend to think short-term and the fundamentalists are people who tend to think long-term. For example, the former may by profession be "traders", people who buy and sell foreign exchange on a short- 
term basis and have evolved different ways of thinking than the latter, who may by profession buy and hold longer-term securities. ${ }^{18}$

In any case, one could interpret the two groups as taking positions in the market directly, rather than merely issuing forecasts for the portfolio managers to read. The market price of foreign exchange would then be determined by demand coming from both groups. But the weights that the market gives to the two change over time, according to the groups' respective wealths. ${ }^{19}$ If the fundamentalists sell the dollar short and keep losing money, while the chartists go long and keep gaining, in the long run the fundamentalists will go bankrupt and there will only be chartists in the marketplace. The model that we develop in the next section pursues the portfolio manager's decision-making problem instead of the marketplace-aggregation idea, but the two are similar in spirit.

Yet another possible interpretation of the survey data is that the two ways of thinking represent conflicting forces within the mind of a single representative agent. When respondents answer the longer-term surveys they give the views that their economic reason tells them are correct. When they get into the trading room they give greater weight to their instincts, especially if past bets based on their economic reason have been followed by ruinous "negative reinforcement." A respondent may think that when the dollar begins its plunge, he or she will be able to get out before everyone else does. This opposing instinctual force comes out in the survey only when the question pertains to the very short term--one or two weeks; it would be too big a contradiction for his conscience if a respondent were to report a one-week expectation of dollar deprecia-

\footnotetext{
18 It sounds strange to describe 3 to 6 months as "long-term." But such descriptions are common in the foreign exchange markets.

19 Figlewski $(1878,1982)$ considers an economy in which private information, weighted by traders' relative wealths, is revealed in the market price.
} 
tion that was (proportionately) just as big as the answer to the 6-month question, at the same time that he or she was taking a long position in dollars. Again, we prefer the interpretation where the survey reflects the true expectations of the respondent, and the market trading is done by some higher authority; but others may prefer the more complex psychological interpretation.

The fragments of empirical evidence in Table 3 are the only ones we will offer by way of testing our approach. The aim in what follows is to construct a model that reconciles the apparent contradictions discussed in Section 2. There will be no hypothesis testing in any sense.

We think of the value of the dollar as being driven by the decisions of portfolio managers who use a weighted average of the expectations of fundamentalists and chartists. Specifically,

$$
\Delta s_{t+1}^{m}=\omega_{t} \Delta s_{t+1}^{f}+\left(1-\omega_{t}\right) \Delta s_{t+1}^{c}
$$

where $\Delta s_{t+1}{ }^{m}$ is the rate of change in the spot rate expected by the portfolio managers, $\Delta s_{t+1}^{f}$ and $\Delta s_{t+1}{ }^{c}$ are defined similarly for the fundamentalists and chartists, and $\omega_{t}$ is the weight given to fundamentalist views. For simplicity we assume $\Delta s_{t+1}^{c}=0$. Thus equation (1) becomes

$$
\Delta s_{t+1}^{m}=\omega_{t} \Delta s_{t+1}^{f}
$$

or

$$
\omega_{t}=\frac{\Delta s_{t+1}^{m}}{\Delta s_{t+1}^{f}}
$$

If we take the 6-month forward discount to be representative of portfolio managers' expectations and the 6-month survey to be representative of fundamentalists' expectations, we can get a rough idea of how the weight, $\omega_{t}$, varies over time. 
Table 4 contains estimates of $\omega_{t}$ from the late 1970 s to the present. (There are, unfortunately, no survey data for 1980.) The table indicates a preponderance of fundamentalism in the late seventies; portfolio managers gave almost complete weight to this view. But beginning in 1981, as the dollar began to rise, the forward discount increased less rapidly than fundamentalists' expected depreciation, indicating that the market (or the portfolio managers in our story) was beginning to pay less attention to the fundamentalists' view. By 1985, the market's expected depreciation had fallen to about zero. According to these computations, fundamentalists are being completely ignored.

While the above scenario solves the paradox posed in proposition (4), it leaves unanswered the question of how the weight $\omega_{t}$, which appears to have fallen dramatically since the late 1970s, is determined by portfolio managers. Furthermore, if portfolio managers have small risk premia, and thus expect depreciation at a rate close to that predicted by the forward discount, we still must account for the spectacular rise of the dollar (proposition (1)), and resolve how the rationally expected depreciation differs from the forward discount (propositions (2) and (3)).

\section{Portfolio Managers and the Dollar}

Up to this point we have characterized the chartist and fundamentalist views of the world, and hinted at the approximate mix that portfolio managers would need to use if the market risk premium is to be near zero. We now turn to an examination of the behavior of portfolio managers, and to the determination of the equilibrium spot rate. In particular, we first focus exclusively on the dynamics of the spot rate which are generated by the changing expectations of portfolio managers. We then extend the framework to include the evolution of fundamentals which eventually must bring the dollar back down. 


\subsection{Expectations and Exchange Rate Dynamics}

A general model of exchange rate determination can be written

$$
s_{t}=c \Delta s_{t+1}^{m}+z_{t}
$$

where $s(t)$ is the $\log$ of the spot rate, $\Delta s_{t+1}^{m}$ is the rate of depreciation expected by "the market" (portfolio managers) and $\mathbf{z}_{\mathbf{t}}$ represents other contemporaneous determinants. This very general formulation, in which the first term can be thought of as speculative factors and the second as fundamentals, has been used by Mussa (1976) and Kohlhagen (1979). An easy way to interpret equation (3) is in terms of the monetary model of Mussa (1976), Frenkel (1976) and Bilson (1978). Then $c$ would be interpreted as the semi-elasticity of money demand with respect to the alternative rate of return (which could be the interest differential, expected depreciation or expected inflation differential; the three are equal if uncovered interest parity and purchasing power parity hold), and $z_{\mathbf{t}}$ would be interpreted as the $\log$ of the domestic money supply relative to the foreign (minus the log of relative income, or any other determinants of real money demand). An interpretation of equation (3) in terms of the portfolio-balance approach is slightly more awkward because of nonlinearity. But we could define

$$
\mathbf{z}_{\mathbf{t}}=d_{t}-f_{t}-c\left(i_{t}-i^{*}\right)
$$

where $d_{t}$ is the log of the supply of domestic assets (including not only money but also bonds and other assets), $f_{t}$ is the $\log$ of the supply of foreign assets, and $i_{t}-i^{*}{ }_{t}$ is the nominal interest differential. Then equation (3) can be derived as a linear approximation to the solution for the spot rate in a system where the share of the portfolio allocated to foreign assets depends on the expected return differential or risk premium, $i_{t}-i^{*}{ }_{t}-\Delta s_{t+1}^{m}$. If investors diversify their portfolios optimally, c can be seen to depend inversely on the 
variance of the exchange rate and the coefficient of relative risk-aversion. ${ }^{20}$ In any case, the key point behind equation (3), common throughout the assetmarket view of exchange rates, is that an increase in the expected rate of future depreciation will reduce demand for the currency today, and therefore will cause it to depreciate today.

The present paper imbeds in the otherwise standard asset pricing model given by equation (3) a form of market expectations that follows equation (1). That is, we assume that portfolio managers' expectations are a weighted average of the expectations of fundamentalists, who think the spot rate regresses to long-run equilibrium, and the expectations of chartists who use time series methods:

$$
\Delta s_{t+1}^{m}=\omega_{t} \Delta s_{t+1}^{f}+\left(1-\omega_{t}\right) \Delta s_{t+1}^{c}
$$

We define $\bar{s}$ to be the logarithm of the long-run equilibrium rate and $\vartheta$ to be the speed of regression of $s_{t}$ to $\bar{s}$. In the view of fundamentalists:

$$
\Delta s_{t+1}^{f}=v\left(\bar{s}-s_{t}\right)
$$

In the context of some standard versions of equation (3) -- the monetary model of Dornbusch (1976) in which goods prices adjust slowly over time or the portfolio-balance models in which the stock of foreign assets adjusts slowly over time -- it can be shown that equation (5) might be precisely the rational form for expectations to take if there were no chartists in the market, $\omega_{t}=1$. Unfortunately for the fundamentalists, the distinction is crucial; equation (5) will not be rational given the complete model.

For example, if we define $z_{t}$ in equation (3) as the interest differential we have

20 See, for example, Frankel (1986). 


$$
s_{t}=\alpha+c \vartheta\left(\bar{s}-s_{t}\right)-b\left(i_{t}-i^{*}\right)
$$

Uncovered interest parity, $i(t)-i^{*}=\vartheta(\bar{s}-s(t))$, implies that $\vartheta=1 /(\beta-c)$ and $\alpha=\bar{s}$. It is then straightforward to show that $\vartheta$ can be rational within the Dornbusch (1976) overshooting model. ${ }^{21}$

In the second group of models (Kouri (1976) and Rodriguez (1980) are references), overshooting occurs because the stock of net foreign assets adjusts slowly through current account surpluses or deficits. A monetary expansion creates an imbalance in investors' portfolios which can be resolved only by an initial increase in the value of net foreign assets. This sudden depreciation of the domestic currency sets in motion an adjustment process in which the level of net foreign assets increases and the currency appreciates to its new steady-state level. In such a model (which is similar to the simulation model below), the rate of adjustment of the spot rate, $\vartheta$, may also be rational, if there are no chartists. Repeating equation (6) but using the log of the stock of net foreign assets instead of the interest differential as the important fundamental, we have in continuous time:

$$
s(t)=\alpha+c v(\bar{s}-s(t))-d f(t)
$$

Suppose the actual rate of depreciation is $\dot{s}(t)=v(\bar{s}-s(t))$. Equation (7) then can be rewritten in terms of deviations from the steady-state levels of the exchange rate and net foreign assets, $\bar{s}$ and $\bar{f}$.

$$
\dot{s}(t)=\frac{-v}{c \vartheta}(\bar{s}-s(t))-\frac{d v}{c \vartheta}(\bar{f}-f(t))
$$

\footnotetext{
21 Assurre that prices evolve slowly according to $\dot{p}=\pi\left(\gamma(s-p)-\sigma\left(i-i^{*}\right)\right.$ ) (where $\gamma$ and $\sigma$ are the elasticities $0^{*}$ goods demand with respect to the real exchange rate and the interest rate, respectively), that the interest rate differential is proportional to the gap between the current and long-run price levels, $\lambda\left(i-i^{*}\right)=p-\underline{p}$ (where $\lambda$ is the semielasticity of money demand with respect to the interest rate) and that the long-run equilibrium exchange rate is given by long-run purchasing power parity, $\bar{s}=\bar{p}$. Then it can be
} shown that rationality implies:

$$
\vartheta=\frac{1}{b-c}=\frac{\pi}{2 \lambda}\left(\gamma \lambda+\sigma+\left(\gamma^{2} \lambda^{2}+2 \lambda \gamma \sigma+\sigma^{2}+4\right)^{3 / 2}\right)
$$


where rationality implies that $v=v$. Following Rodriguez (1980), the normalized current account surplus may also be expressed in deviations from steadystate equilibrium:

$$
\dot{f}=-q(\bar{s}-s(t))+\gamma(\bar{f}-f(t))
$$

where $q$ and $\gamma$ are the elasticities of the current account with respect to the exchange rate and the level of net foreign assets, respectively. The system of equations (8) and (9) then has the rational expectations solution:

$$
\vartheta=\frac{c \gamma-1+\left((1-c \gamma)^{2}+4 c(\gamma+d q)\right)^{\not h}}{2 c}
$$

\subsection{The Model with Exogenous Fundamentals}

We now turn to describe the model, assuming for the time being that important fundamentals remain fixed. Regardless of which specification we use for the fundamentals, the existence of chartists whose views are given timevarying weights by the portfolio managers complicates the model. For simplicity, we study the case in which the chartists believe the exchange rate follows a random walk, $\Delta s_{t+1}^{c}=0$. Thus equation (1) becomes

$$
\Delta s_{t+1}^{m}=\omega_{t} v\left(\bar{s}-s_{t}\right)
$$

Since the changing weights by themselves generate self-sustaining dynamics, the expectations of fundamentalists will no longer be rational, except for the trivial case in which fundamentalist and chartist expectations are the same, $v=0$.

The "bubble" path of the exchange rate will be driven by the dynamics of portfolio managers' expected depreciation. We assume that the weight given to fundamentalist views by portfolio managers, $\omega_{t}$, evolves according to:

$$
\Delta \omega_{t}=\delta\left(\hat{\omega}_{t-1}-\omega_{t-1}\right)
$$


$\hat{\omega}_{t-1}$ is in turn defined as the weight, computed ex post, that would have accurately predicted the contemporaneous change in the spol rate, defined by the equation:

$$
\Delta s_{t}=\hat{\omega}_{t-1} \vartheta\left(\bar{s}-s_{t-1}\right)
$$

Equations (11) and (12) give us:

$$
\Delta \omega_{t}=\delta \frac{\Delta s_{t}}{v\left(\bar{s}-s_{t-1}\right)}-\delta \omega_{t-1}
$$

The coefficient $\delta$ in equation (13) controls the adaptiveness of $\omega_{t}$.

One interpretation for $\delta$ is that it is chosen by portfolio managers who use the principles of Bayesian inference to combine prior information with actual realizations of the spot process. This leads to an expression for $\delta$ which changes over time. To simplify the following analysis we assume that $\delta$ is constant; in the first appendix we explore more precisely the problem that portfolio managers face in choosing $\delta$. The results that emerge there are qualitatively similar to those that follow here.

Taking the limit to continuous time, we can rewrite equation (13) as

$$
\begin{gathered}
\dot{\omega}(t)=\delta\left(\frac{\dot{s}(t)}{\vartheta(\bar{s}-s(t))}-\omega(t)\right) \text { if } 0<\omega(t)<1 \\
\text { if } \omega(t)=0 \text { then } \begin{cases}\dot{\omega}(t)=0 \quad \text { if } \dot{s}(t) \leq 0 \\
\dot{\omega}(t)=-\frac{\delta \dot{s}(t)}{\vartheta(\bar{s}-s)} \text { if } \dot{s}(t)>0\end{cases} \\
\dot{\omega}(t)=0 \quad \text { then }\left\{\begin{array}{l}
\dot{\omega}(t) \geq \vartheta(\bar{s}-s(t)) \\
\dot{\omega}(t)=\frac{\delta \dot{s}(t)}{v(\bar{s}-s(t))}-\delta
\end{array}\right.
\end{gathered}
$$


where a dot over a variable indicates the total derivative with respect to time. The restrictions that are imposed when $\omega(t)=0$ and $\omega(t)=1$ are to keep $\omega(t)$ from moving outside the interval $[0,1]$. These restrictions are in the spirit of the portfolio managers choice set: the portfolio manager can at most take one view or the other exclusively.

The evolution of the spot rate can be expressed by taking the derivative of equation (3) (for now holding $z$ and the long-run equilibrium, $\bar{s}$, constant)

$$
\dot{s}(t)=\left(\frac{\dot{\omega}(t) c v}{1+c \vartheta \omega(t)}\right)(\bar{s}-s(t))
$$

Equations (14) and (15) can be solved simultaneously and rewritten, for interior values of $\omega$, as

$$
\begin{gathered}
\dot{\omega}(t)=\frac{-\delta \omega(t)(1+c \vartheta \omega(t))}{1+c \vartheta \omega(t)-\delta c} \text { if } 0<\omega(t)<1 \\
\dot{s}(t)=\left(\frac{-\delta \omega(t) c \vartheta}{1+c \vartheta \omega(t)-\delta c}\right)(\bar{s}-s(t))
\end{gathered}
$$

In principle, an analytic solution to the differential equation (16) could be substituted into (17), and then (17) could be integrated directly.22 For our purposes it is more desirable to use a finite difference method to simulate the motion of the system. In doing so we must pick values for the coefficients, $c, \vartheta$ and $\delta$, and starting values for $\omega(t)$ and $s(t)$.

To exclude any unreasonable time paths implied by equations (16) and (17), we impose the obvious sign restrictions on the coefficients. The parameter $\vartheta$ must be positive and less than one if expectations are to be regressive, that is, if they are to predict a return to the long-run equilibrium at a finite rate. By

\footnotetext{
22 In this case, however, $\omega(t)$ does not have a closed analytic form.
} 
definition, $\delta$ and $\omega(t)$ lie in the interval $[0,1]$ since they are weights. The coefficient $c$ measures the responsiveness of the spot rate to changes in expected depreciation and must be positive to be sensible.

These restrictions, however, are not enough to determine unambiguously the sign of the denominator of equations (16) and (17). The three possibilities are that: $1+c \vartheta \omega(t)-\delta c<0$ for all $\omega_{i} 1+c \vartheta \omega(t)-\delta c>0$ for all $\omega$; and $\begin{aligned} & < \\ 1+c \vartheta \omega(t)-\delta c & =0 \text { as } \omega(t)=\omega^{*}, \text { where } 0<\omega^{*}<1,23 \\ & >>\end{aligned}$

If $1+c \vartheta \omega(t)-\delta c<0$, the system will be stable and will tend to return to the long-run equilibrium from any initial level of the spot rate. This might be the case if portfolio managers use only the most recent realization of the spot rate to choose $\omega(t)$, that is, if $\delta \approx 1$. If, on the other hand, portfolio managers give substantial weight to prior information so that $\delta$ is small, the expression $1+c v \omega(t)-\delta c$ will be positive. In this case the spot rate will tend to move away from the long-run equilibrium if it is perturbed.

Let us assume that portfolio managers are slow learners. 24 What does this assumption imply about the path of the dollar? If we take as a starting point the late $1970 \mathrm{~s}$, when $s(t) \approx \bar{s}$ and when $\omega_{t} \approx 1$ (as the calculations presented in

Rs We do not consider the third case, because equations (16) and (17) are not defined at $1+c \vartheta \omega(t)-\delta c=0$.

24 The following intuition may help see why the system is stable when portfolio managers are "fast" learners and unstable when they are "slow" learners. Suppose the value of the dollar is above $\bar{s}$, so that portfolio managers are predicting depreciation at the rate $\omega v(\bar{s}-s(t))$. If the spot rate were to start depreciating at a rate slightly faster than this, portfolio managers would then shift $\omega(t)$ upwards, in favor of the fundamentalists. Under what circumstances would these hypothesized dynamics be an equilibrium? Recall from equations (14) and (15) that if $\delta$ is big, portfolio managers place substantial weighi on new information. The larger is $\delta$, the more quickly the spot rate changes. It is easy to show that if portfolio managers are fast learners (i.e., if $\delta>1 / c+v \omega$ ), they update $\omega$ so rapidly that the resulting rate of depreciation must in fact be greater than $\omega v(\bar{s}-s(t))$. Thus the system is stable. Alternatively, if portfolio managers are "slow" learners, $\delta<1 / c+\vartheta \omega$, they heavily discount new information and therefore change $\omega(t)$ too slowly to generate a rate of depreciation greater than $\omega \vartheta(\bar{s}-s(t))$. Li we instead hypothesize an initial rate of depreciation which is less than $\omega \vartheta(s b-s(t))$, portiolio managers would tend to shift $\omega$ downwards, more towards the chartists. From equation (15), a negative $\dot{\omega}(t)$ causes the spot rate to appreciate. Thus slow learning will tend to drive the spot rate further away from the long-run equilibrium (given $0<\omega<1$ ), making the system unstable. 
Table 4 suggest), equation (17) says that the spot rate is in equilibrium, that $\dot{s}(t)=0$. From equation $(14 \mathrm{~b})$, we see that $\dot{\omega}(t)=0$ as well. Thus the system is in a steady-state equilibrium, with market expectations exclusively reflecting the views of fundamentalists.

But given that $1+c \vartheta \omega(t)-\delta c>0$, this equilibrium is unstable, and any shock starts things in motion. Suppose that there is an unanticipated appreciation (the unexpected persistence of high long-term US interest rates in the early $1980 \mathrm{~s}$, for example). The sign restrictions imply that $\omega(t)$ is unambiguously falling over time. Equation (16) says that the chartists are gaining prominence, since $\dot{\omega}(t)<0$. The exchange rate begins to trace out a bubble path, moving away from long-run equilibrium; equation (17) shows that $s(t)<0$ when $\bar{s}>s(t)$. This process cannot, however, go on forever, because market expectations are eventually determined only by chartist views. At this point the bubble dynamics die out since both $\omega(t)$ and $\dot{\omega}(t)$ fall to zero. From equation (17), the spot rate then stops moving away from long-run equilibrium, as it approaches a new, higher equilibrium level where $\dot{s}(t)=0$. In the words of Dornbusch (1983), the exchange rate is both high and stuck.

Figures 1 and 2 trace out a "base-case" simulation of the time profile of the spot rate and $\omega$. They are intended only to suggest that the model can potentially account for a large and sustained dollar appreciation. The figures assume that the dollar is perturbed out of a steady state equilibrium where $\bar{s}=s(t)$ and $\omega(0)=1$ in October 1980. The dollar rises at an decreasing rate until sometime in 1985, when, as can be seen in Figure 2, the simulated weight placed on fundamentalist expectations becomes negligible. A steady state obtains at a new higher level, about 31 percent above the long-run equilibrium implied by purchasing power parity. Although we tried to choose reasonable values for the parameters used in this example, the precise level of the plateau and the rate 
Figure 1

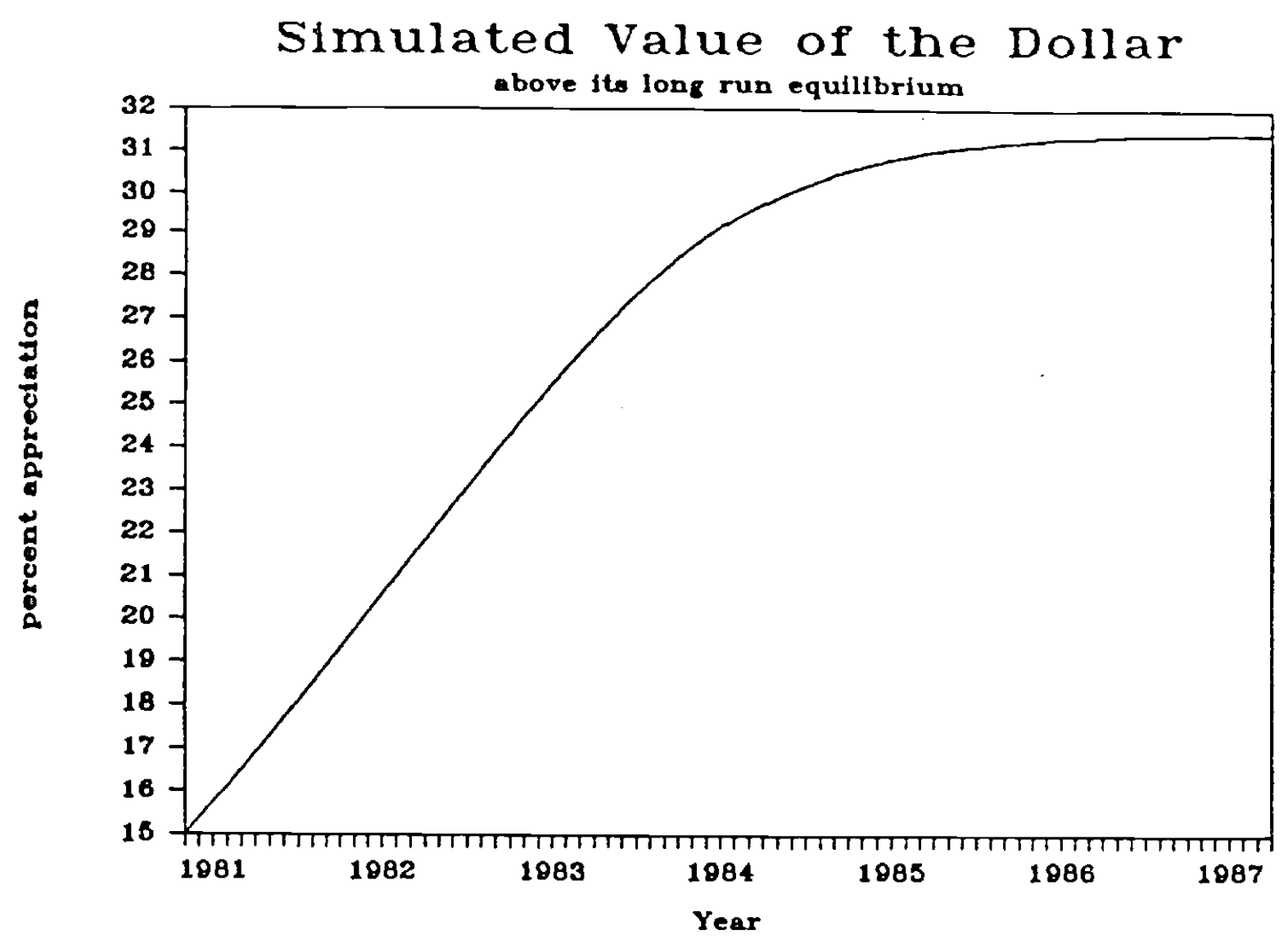

Figure 2

Simulated Weight Placed on Fundamental-

$\omega$

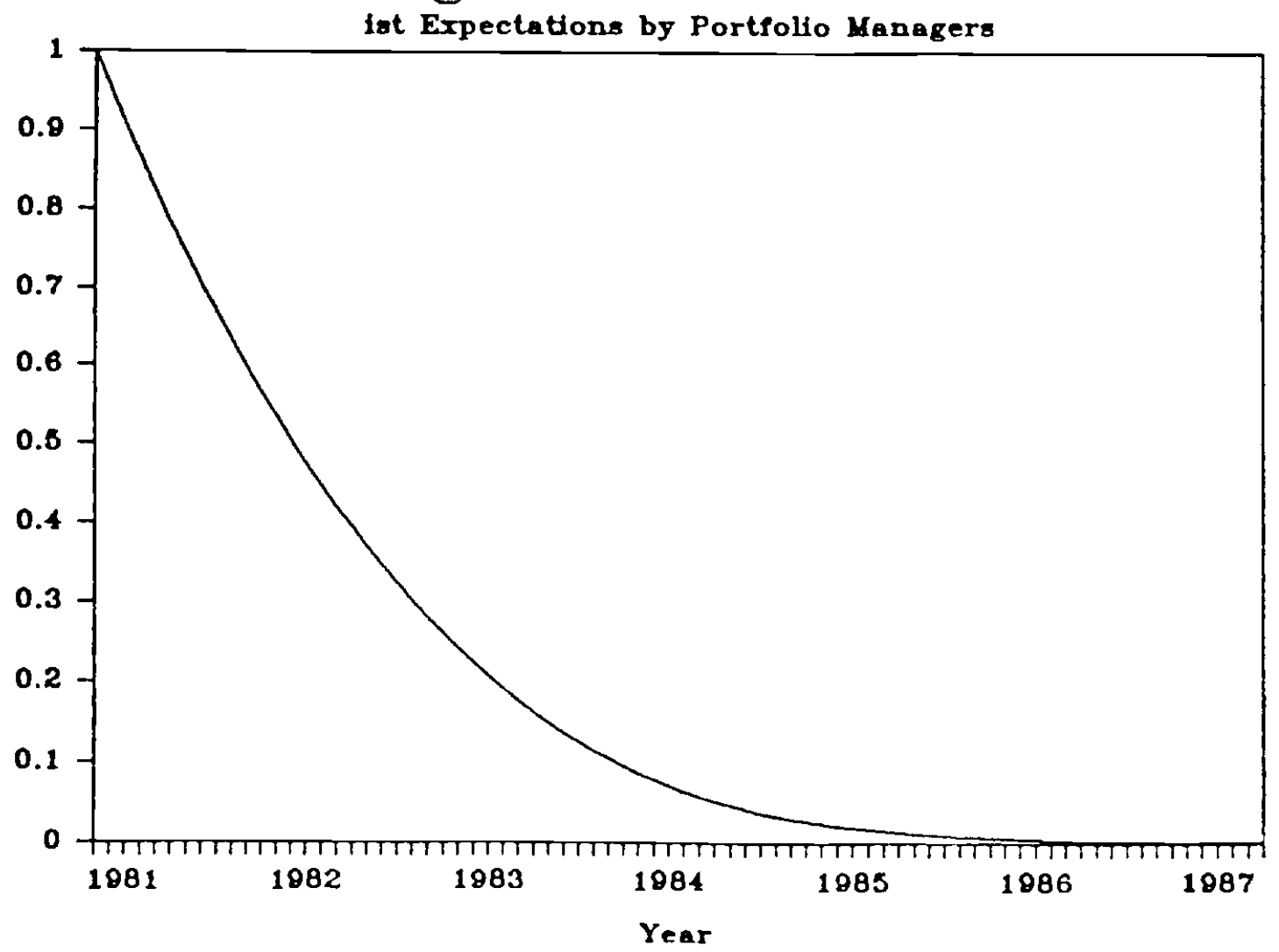


at which the currency approaches it are sensitive to different choices of parameters. In the second appendix we give more detail on values used in the simulation.

It is worth emphasizing that the equilibrium spot rate appreciates along its bubble path even though none of the actors expects appreciation. This result is due to the implicit stock adjustment taking place. As portfolio managers reject their fundamentalist roots, they reshuffe their portfolios to hold a greater share in dollar assets. For fixed relative asset supplies, a greater dollar share can be obtained in equilibrium only by additional appreciation. This unexpected appreciation, in turn, further convinces portfolio managers to embrace chartism. The rising dollar becomes self-sustaining. In the end, when the spiral finally levels off at $\omega(t)=0$, the level at which the currency becomes stuck represents a fully rational equilibrium: portfolio managers expect zero depreciation and the rate of change of the exchange rate is indeed zero.

What we term the irrationality of the model can be seen by inspecting equation (17). Recall that market expected depreciation, that of portfolio managers, is a weighted average of chartist and fundamentalist expectations, $\omega(t) \vartheta(\bar{s}-s(t))$. But the actual, or rational, expected rate of depreciation is given by $\left(\frac{-\delta c}{1+c v \omega(t)-\delta c}\right) \omega(t) \vartheta(\bar{s}-s(t))$. The two are not equal, unless $\omega=0.25$ The problem we gave portfolio managers was to pick $\omega(t)$ in a way that best describes the spot process they observe (together with the prior confidence they had in fundamentalist predictions). But theirs is a thankless task, since the spot process is more complicated.

25 There is a second root, $\omega=-1 /\left(\vartheta_{c}\right)$, which we rule out since it is less than zero. 


\subsection{The Model with Endogenous Fundamentals}

The results so far offer an explanation for the paradox of proposition (1), that sustained dollar appreciation occurs even though all agents expect depreciation. But a spot rate that is stuck at a disequilibrium level is an unlikely end for any reasonable story. The next step is to specify the mechanism by which the unsustainability of the dollar is manifest in the model.

The most obvious fundamental which must eventually force the dollar down is the stock of net foreign assets. Reductions in this stock, through large current account deficits, cannot take place indefinitely. Sustained borrowing would, in the long run, raise the level of debt above the present discounted value of income. But long before this point of insolvency is reached, the gains from a U.S. policy aimed at reducing the outstanding liabilities (either through direct taxes or penalties on capital, or through monetization) would increase in comparison to the costs. If foreigners associate large current account deficits with the potential for moral hazard, they would treat U.S. securities as increasingly risky and would force a decline in the level of the dollar.

To incorporate the effects of current account imbalances, we consider the model, similar to Rodriguez (1980), given in equation (7):

$$
s_{t}=\alpha+c \Delta s_{t+1}^{m}-d f
$$

where $\Delta s_{t+1}^{m}$ is defined in equation (1a) and where $f$ represents the log of cumulated US current account balances. The coefficient, $d$, is the semielasticity of the spot rate with respect to transfers of wealth, and must be positive to be sensible. The differential equations (16) and (17) now become:

$$
\begin{gathered}
\dot{\omega}(t)=\left(\frac{\delta}{1+c \vartheta \omega(t)-\delta c}\right)\left(-w(t)(1+c v \omega(t))-\frac{d \dot{f}}{v(\bar{s}-s(t))}\right) \text { if } 0<\omega(t)<1 \\
\dot{s}(t)=\frac{-\delta \omega(t) c \vartheta(\bar{s}-s(t))+d \dot{f}}{1+c \omega(t) v-\delta c}
\end{gathered}
$$


If we were to follow the route of trying to solve analytically the system of differential equations, we would add a third equation giving the "normalized" current account, $\dot{f}$, as a function of $s(t)$. (See, for example, equation (9) above.) But we here instead pursue the simulation approach.

In the simulation we use actual current account data for $\dot{f}$, the change in the stock of net foreign assets. Figures 3 and 4 trace out paths for the differential equations (19) and (20). During the initial phases of the dollar appreciation, the current account, which responds to the appreciation with a lag, does not noticeably affect the rise of the dollar. But as $\omega$ becomes small, the spot rate becomes more sensitive to changes in the level of the current account, and the external deficits of 1983-1985 quickly turn the trend. When $\omega$ is small and portfolio managers observe an incipient depreciation of the dollar, they begin to place more weight on the forecasts of fundamentalists, thus accelerating the depreciation initiated by the current account deficits. There is a "fundamentalist revival." Ironically, fundamentalists are initially driven out of the market as the dollar appreciates, even though they are ultimately right about its return to $\bar{s}$.

Naturally, all of our results are sensitive to the precise parameters chosen. To gain an idea of the various sensitivities, we report in Table 5 results using alternative sets of parameter values in the simulation of Figure 3 (or equation (20)). While there is some variation, the qualitative pattern of bubble appreciation, followed by a slow turnaround and bubble depreciation, remains evident in all cases.

Recall that one of the main aims of the model is to account for the two seemingly contradictory facts given by propositions (2) and (3): first that market efficiency test results imply that the rationally expected rate of dollar depreciation has been less than the forward discount, and second that the cal- 
Figure 3

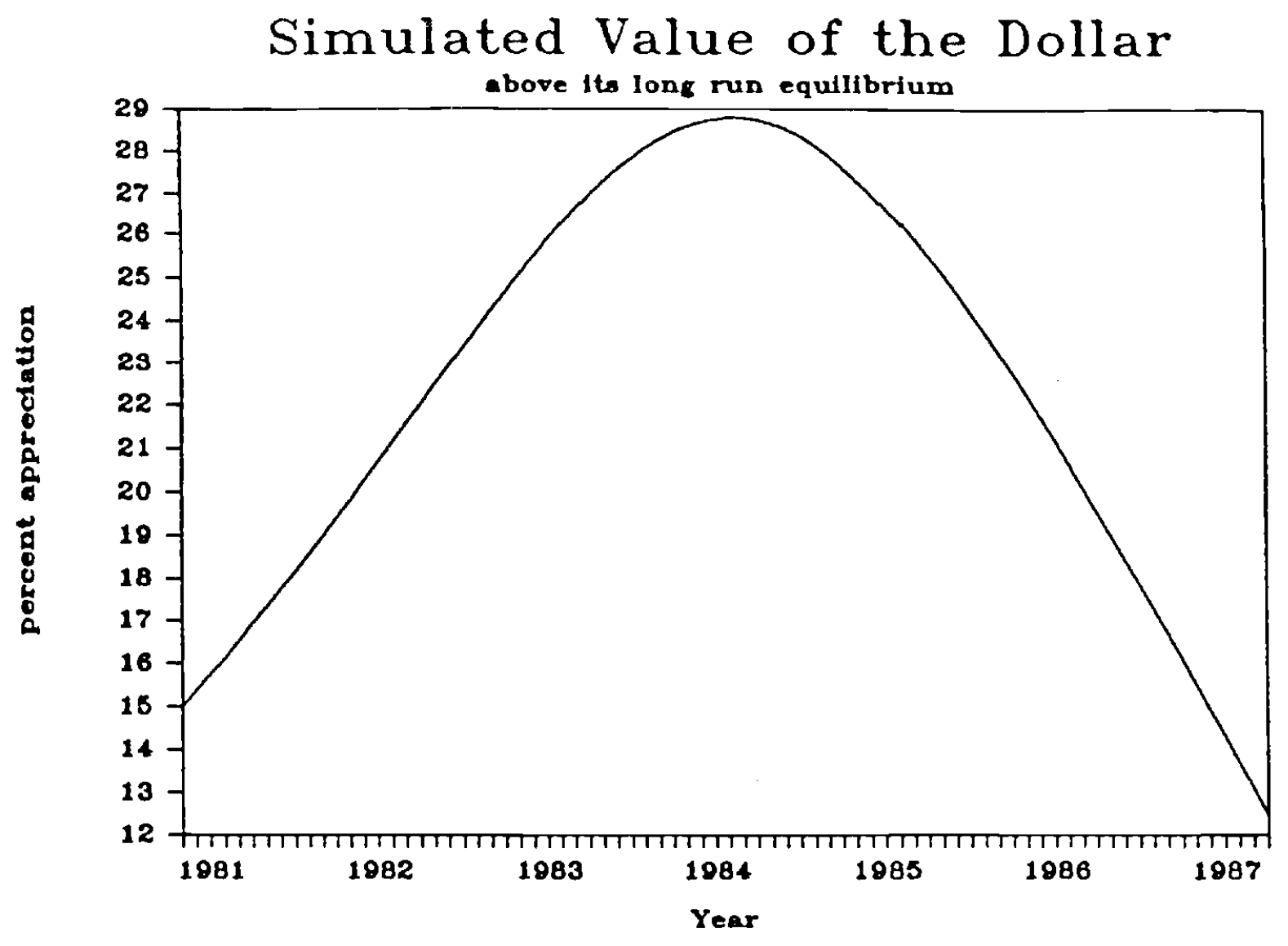

Figure 4

Simulated Weight Placed on Fundamental-

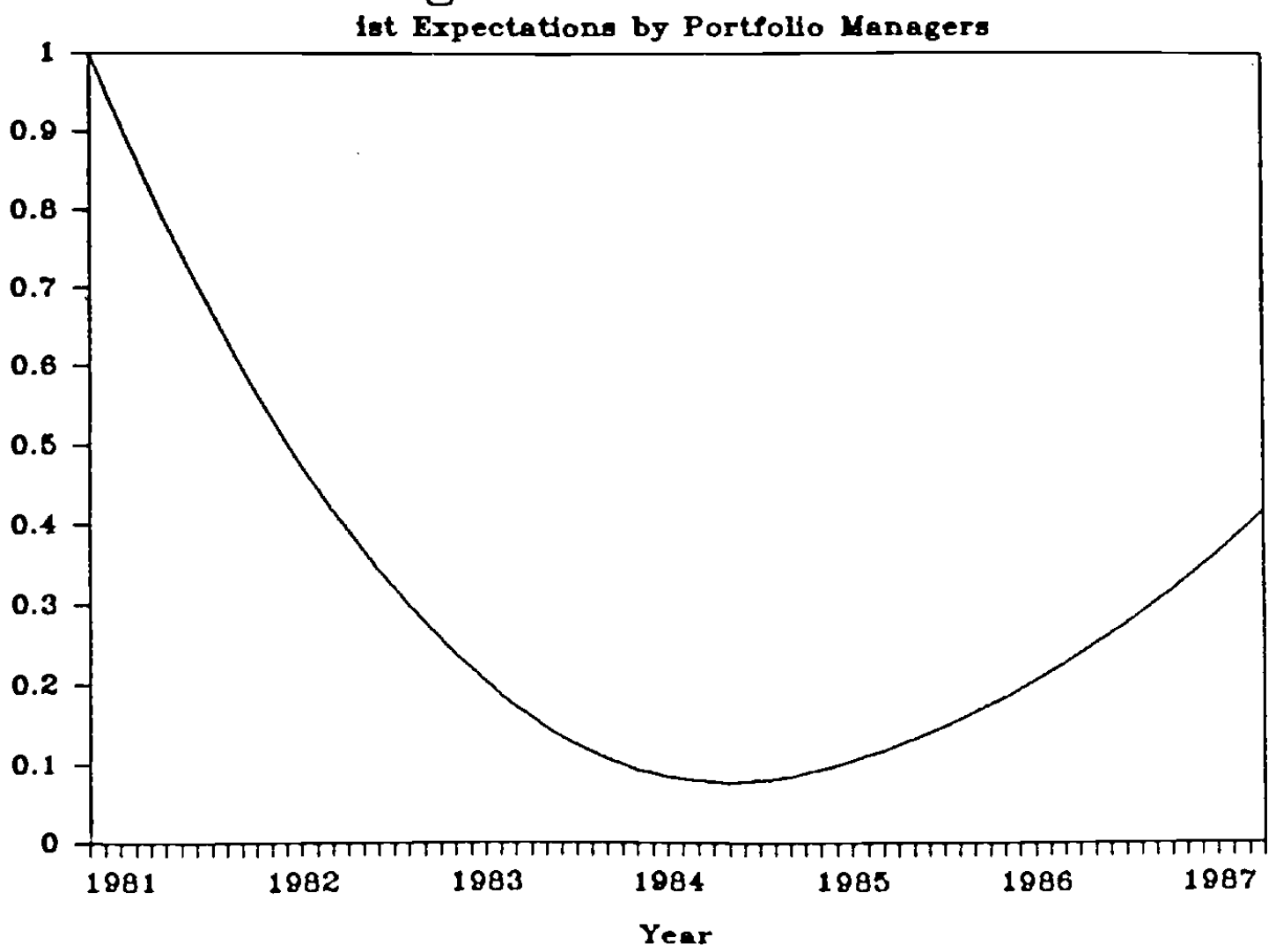




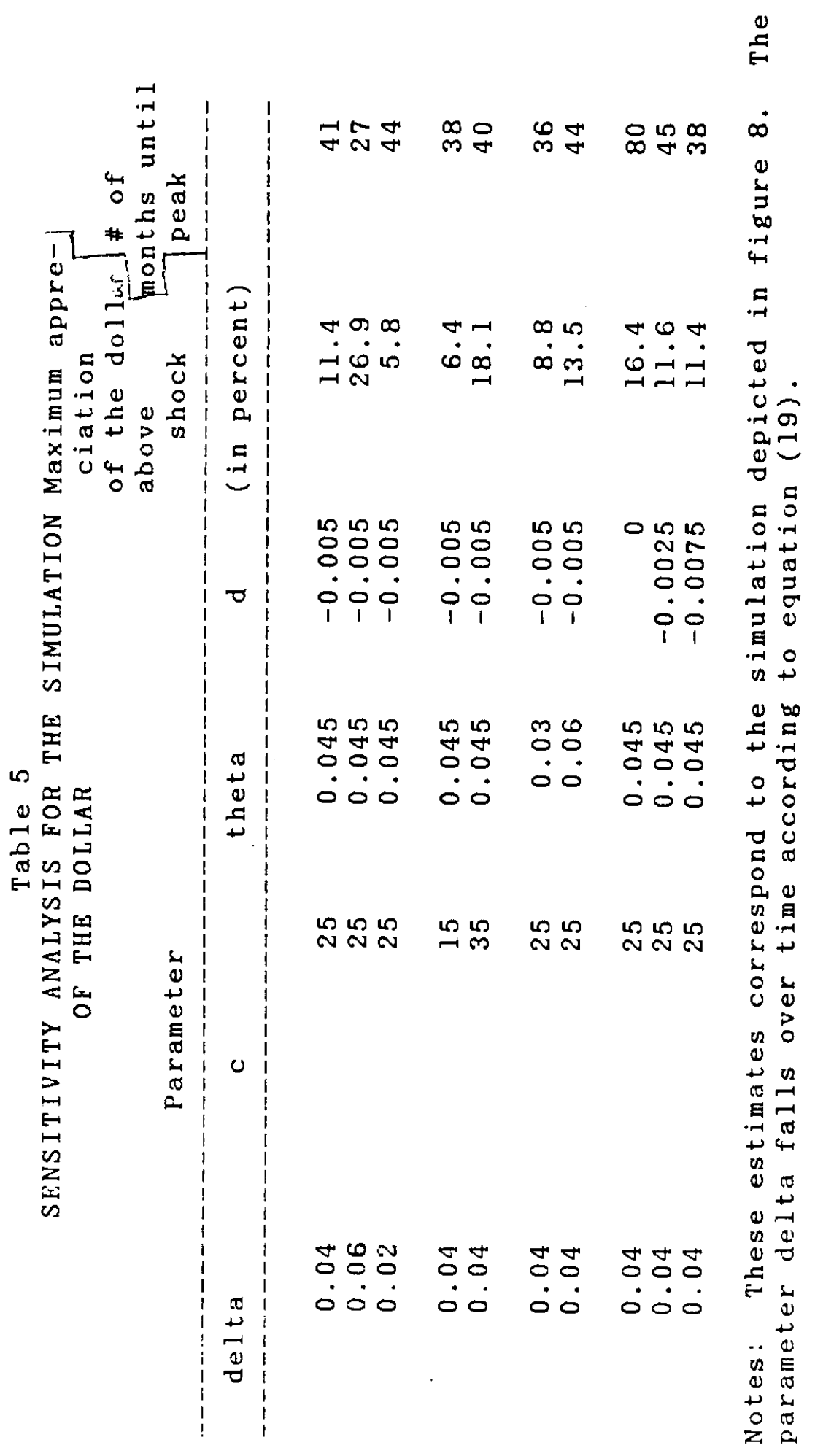


culations based on fundamentals, such as those by Krugman and Marris, imply that the rationally expected rate of depreciation, by 1985 , became greater than the forward discount.

Table 6 clarifies how the model resolves this paradox. The first two lines show the expectations of our two forecasters, the chartists and fundamentalists. The third line repeats the six-month survey expectations to demonstrate that they may in fact be fairly well described by the simple regressive formulation we use to represent fundamentalist expectations in line two. The fourth line contains the expected depreciation of the portfolio managers. Note that these expectations are close to the forward discount in line six, even though the forecasts of the fundamentalists and of the chartists are not. Since only the portfolio managers are hypothesized to take positions in the market, we can say that the magnitude of the market risk premium is small (as mean-variance optimization would predict). Finally, line five shows the actual depreciation in the simulation, which is equivalent to the rationally expected depreciation given the model above. (Of course, none of the agents has the entire model in his information set.) Notice that during the 1981-1984 period, the rationally expected depreciation is not only significantly less than the forward discount, but less than zero. This pattern agrees with the results of market efficiency tests discussed earlier. But the rationally expected depreciation is increasing over time. Sometime in late 1984 or early 1985, the rationally expected rate of depreciation becomes positive and crosses the forward discount. As calculations of the Krugman-Marris type would indicate, rationally expected depreciation is now greater than the forward discount. The paradox of propositions (2) and (3) is thus resolved within the model.

All this comes at what might seem a high cost: portfolio managers behave irrationally in that they do not use the entire model in formulating their 
品

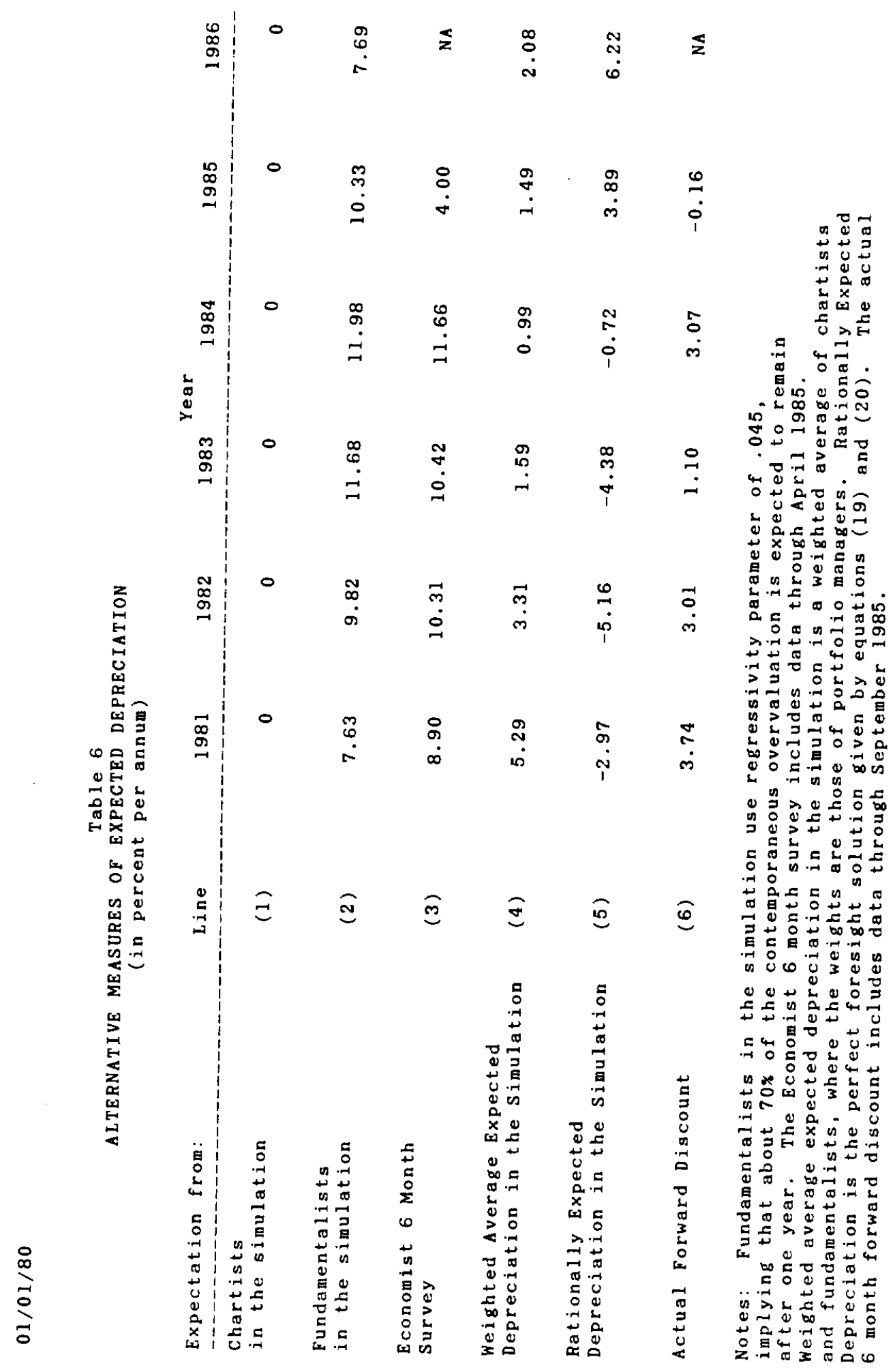


exchange rate forecasts. But another interpretation of this behavior is possible, in that portfolio managers are actually doing the best they can in a confusing world. Within this framework they cannot have been more rational; abandoning fundamentalism more quickly would not solve the problem in the sense that their expectations would not be validated by the resulting spot process in the long run. In trying to learn about the world after a regime change, our portfolio managers use convex combinations of models which are already available to them and which have worked in the past. In this context, rationality is the rather strong presumption that one of the prior models is correct. It is hard to imagine how agents, after a regime change, would know the correct model. 


\section{Conclusions and Extensions}

This paper has posed an unorthodox explanation for the recent aerobatics of the dollar. The model we use assumes less than fully rational behavior in the sense that none of the three classes of actors (chartists, fundamentalists and portfolio managers) condition their forecasts on the full information set of the model. In effect, the bubble is the outcome of portfolio managers' attempt to learn the model. When the bubble takes off (and when it collapses), they are learning more slowly about the model than they are changing it by revising the linear combination of chartist and fundamentalist views they incorporate in their own forecasts. But as the weight given to fundamentalists approaches zero or one, portfolio managers' estimation of the true force changing the dollar comes closer to the true one. These revisions in weights become smaller until the approximation is perfect: portfolio managers have "caught up," by changing the model more slowly than they learn. In this sense the inability of agents with prior information to bring about immediate convergence to a rational expectations equilibrium may provide a framework in which to view "bubbles" in a variety of asset markets.

Several extensions of the model in this paper would be worthwhile. First, it would be desirable to allow chartists to use a class of predictors richer than a simple random walk. They might form their forecasts of future depreciation by using ARIMA models, for example. Simple bandwagon or distributed lag expectations for chartists would be the most plausible since they capture a wide range of effects and are relatively simple analytically. Second, we might want to consider extensions which give the model local stability in the neighborhood of $\omega=1$. Small perturbations from equilibrium would then not instantly cause portfolio managers to begin losing faith in fundamentalist counsel. Only sufficiently large or prolonged perturbations, would upset portfolio managers' 
$-35-$

views enough to cause the exchange rate to break free of its fundamental equilibrium. 


\section{APPENDIX 1}

In this section we consider the problem which portfolio managers face:how much weight should they give to new information concerning the "true" level of $\omega(t)$. After we obtain an explicit formulation for these optimal Bayesian weights, we report their effects on the simulated path of the dollar.

Even though in the model of the spot rate given by equation (3) the value of the currency is fully deterministic, individual portfolio managers who are unable to predict accurately ex ante changes in the spot rate may view the future spot rate as random. They would then form predictions of future depreciation on the basis of observed exchange rate changes and their prior beliefs. At each point in time, portfolio managers therefore view future depreciation as the sum of their current optimal predictor and a random term,

$$
\Delta s_{t+1}=\omega_{t} \vartheta\left(\bar{s}-s_{t}\right)+\varepsilon_{t+1}
$$

where $\varepsilon_{t+1}$ is a serially uncorrelated normal random variable with mean 0 and variance $\vartheta\left(\bar{s}-s_{t-1}\right) / r .^{26}$ Using Bayes' rule, the coefficient $\omega_{t}$ may be written as a weighted average of the previous period's estimate, $\omega_{t-1}$, and information obtained from the contemporaneous realization of the spot rate,

$$
\omega_{t}=\frac{T_{t}}{T_{t}+r} \omega_{t-1}+\frac{r}{T_{t}+r}\left(\frac{\Delta s_{t}}{v\left(\bar{s}-s_{t-1}\right)}\right)
$$

where $T_{t}=T_{t-1}+r$. Thus, if portfolio managers use Bayesian techniques, the weight they would give to the current period's information may be expressed as

$$
\delta_{t}=r /\left(r t+T_{0}\right)
$$

26 The assumption that $\varepsilon_{t+1}$ exhibits such conditional heteroscedasticity results in a particularly convenient expression for $\delta$ (equation (A2) below). Under the assumption that $\varepsilon_{t+1}$ is distributed normally $\left(0, \sigma^{2}\right), \delta_{t}$ depends on all past values of the spot rate, $\delta_{t}=r /\left(r \vartheta \sum\left(\bar{s}-s_{t-i}\right)+T_{0}\right)$.

$$
i=1
$$


where $T_{0}$ is the precision of portfolio managers' prior information.27 Equation (A3) shows that the weight which portfolio managers give to new information would fall over time as decision makers gain more confidence in their prior distribution, or as the prior distribution for the future change in the spot rate converges to the actual posterior distribution. If, however, portfolio managers suspect that the spot rate is nonstationary, past information would be discounted relative to more recent observations. Instead of combining prior information in the form of an OLS regression of actual depreciation on fundamentalist expectations (as they do above), portfolio managers might use a varying parameter technique to take into account the nonstationarity. In this case, the weight they put on new information might not decline over time to zero.

Computing $\delta_{t}$ using equation (A3) does not change substantially the results of the simulations presented in the text. Nevertheless the following pages contain the outcome of simulations using Bayesian $\delta$ 's. Figures 5 and 6 give $s(t)$ and $\omega(t)$ holding fundamentals constant (note that the spot rate approaches the higher equilibrium more slowly than in the comparable figures in the text, Figures 1 and 2). Figures 7 and 8 add to this changing fundamentals according to equations (19) and (20) in the text. Table 7 reports the simulated expectations of our three sets of agents as well as the rationally expected depreciation, comparable to Table 6 in the text.

\footnotetext{
27 If the prior distribution is normal, the precision is equal to the reciprocal of the variance.
} 
Figure 5

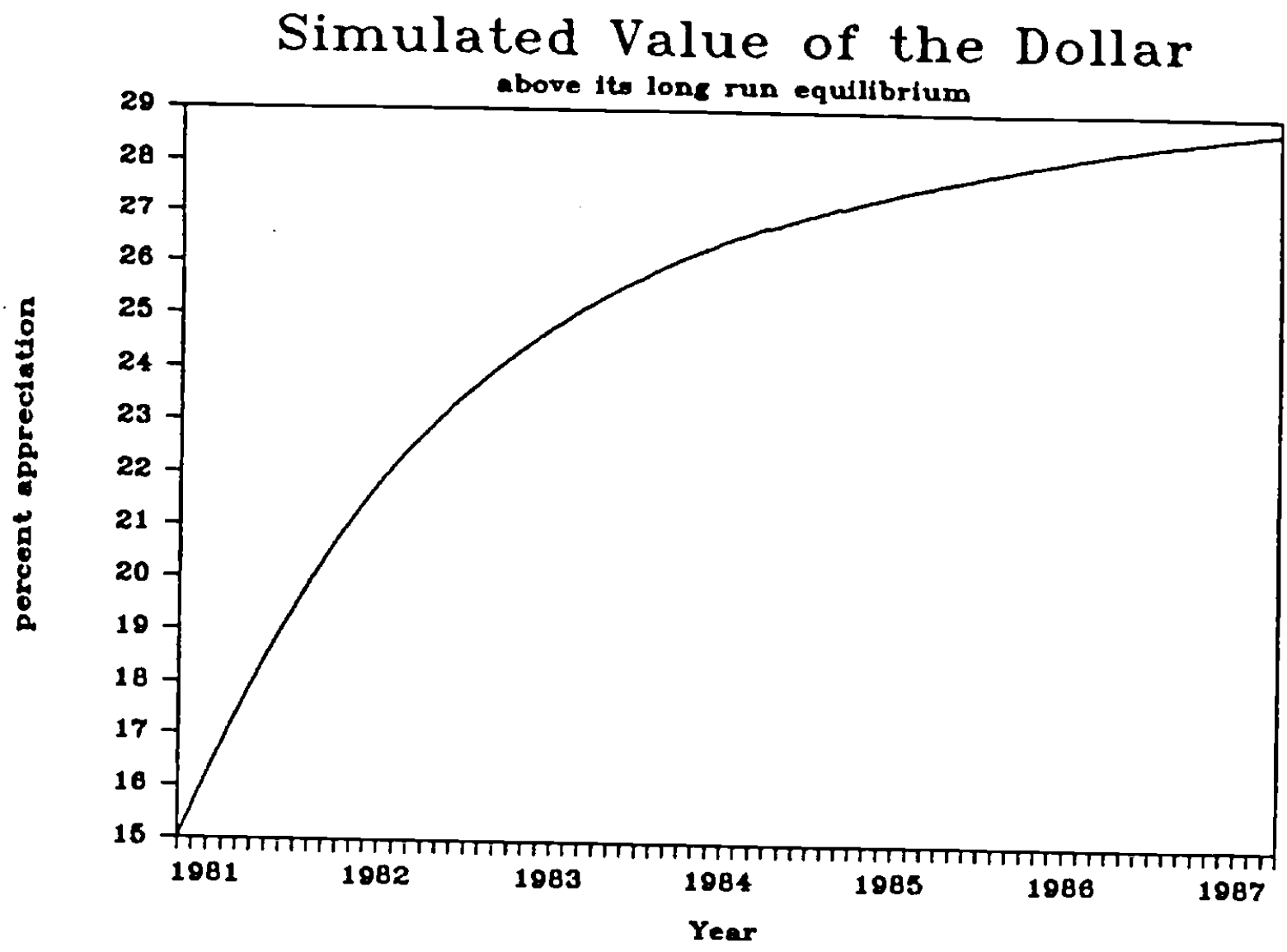

Figure 6

Simulated Weight Placed on Fundamental-

$\omega$

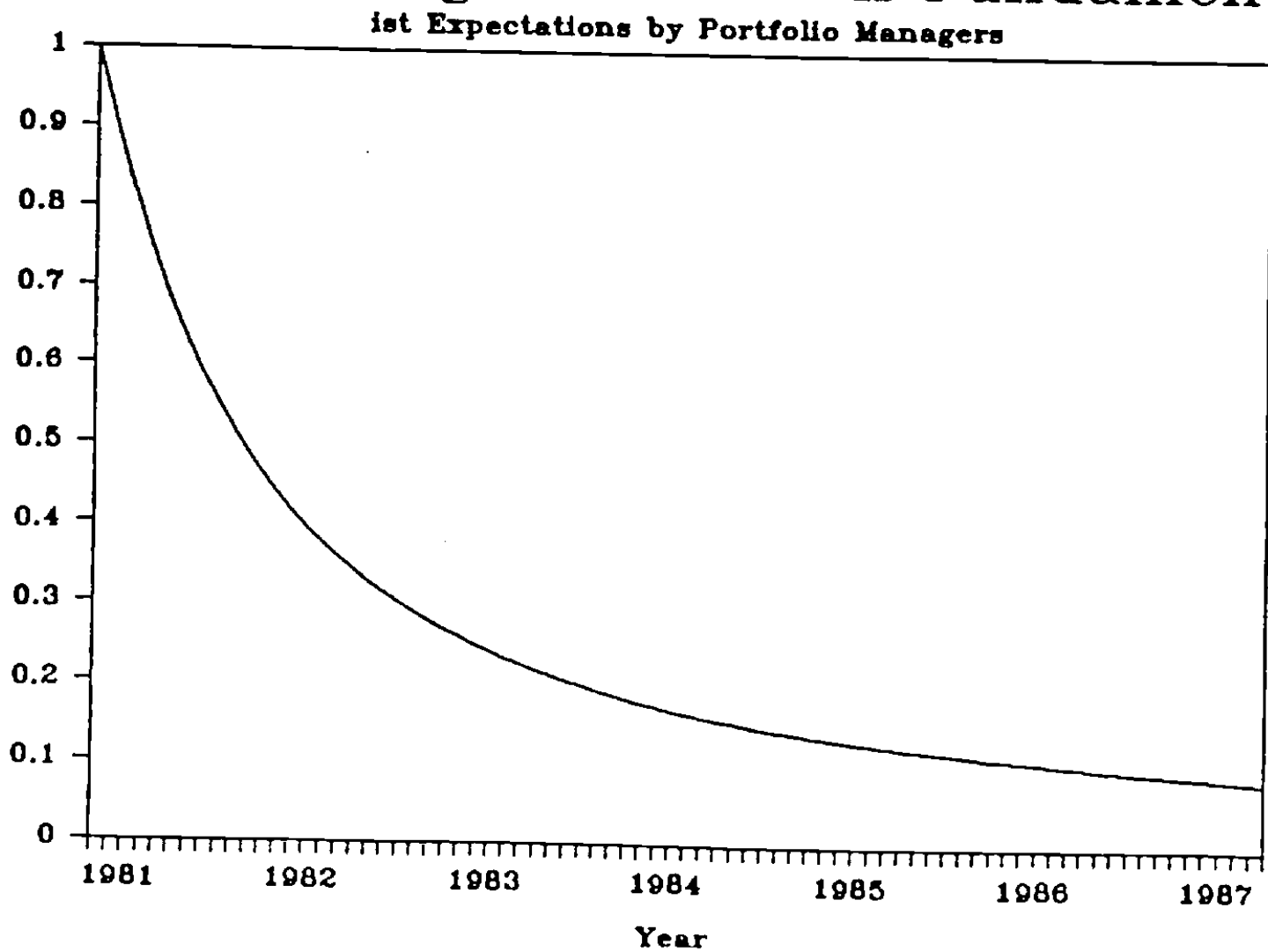


Figure '

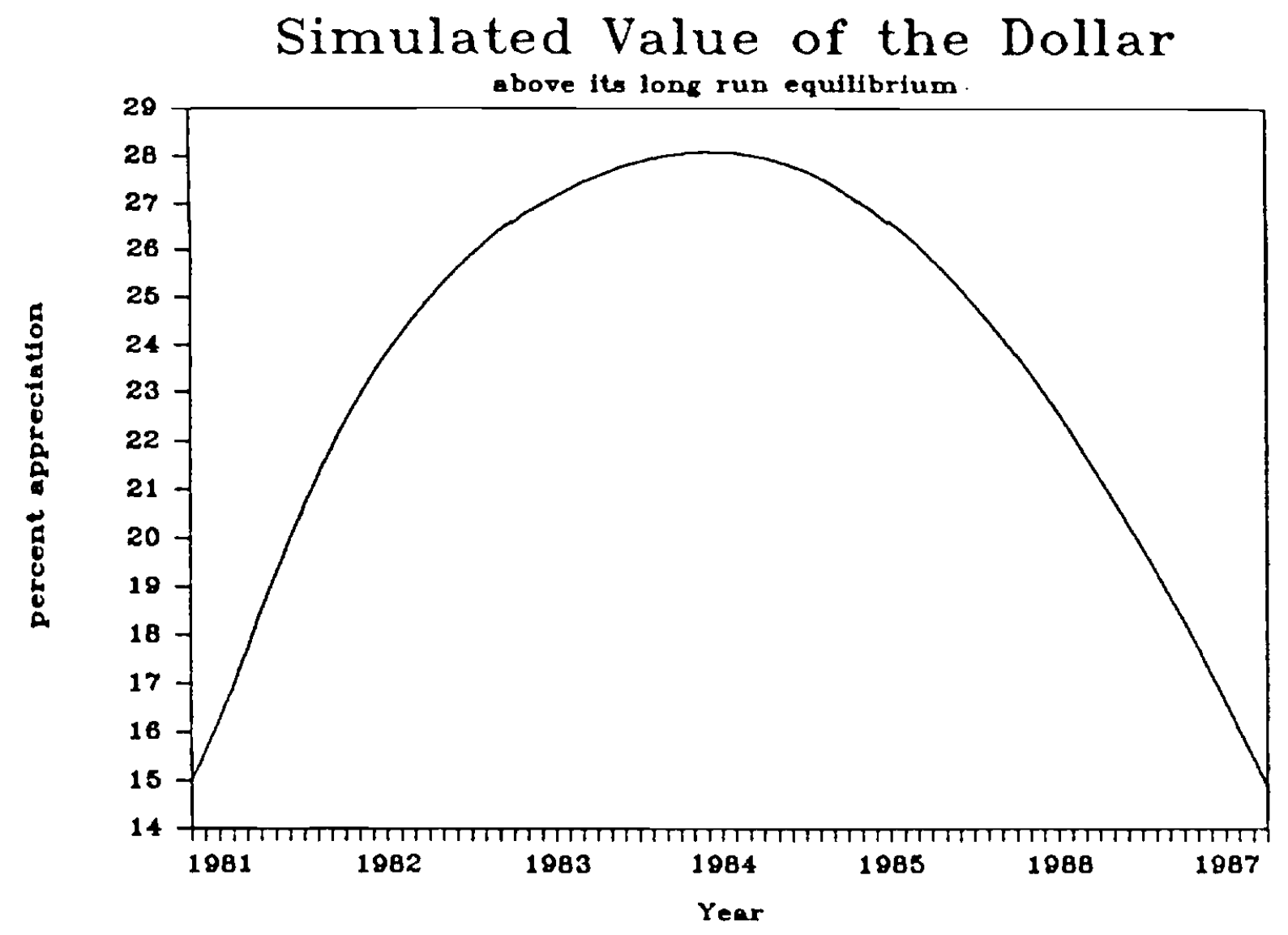

Figure 8

Simulated Weight Placed on Fundamental-

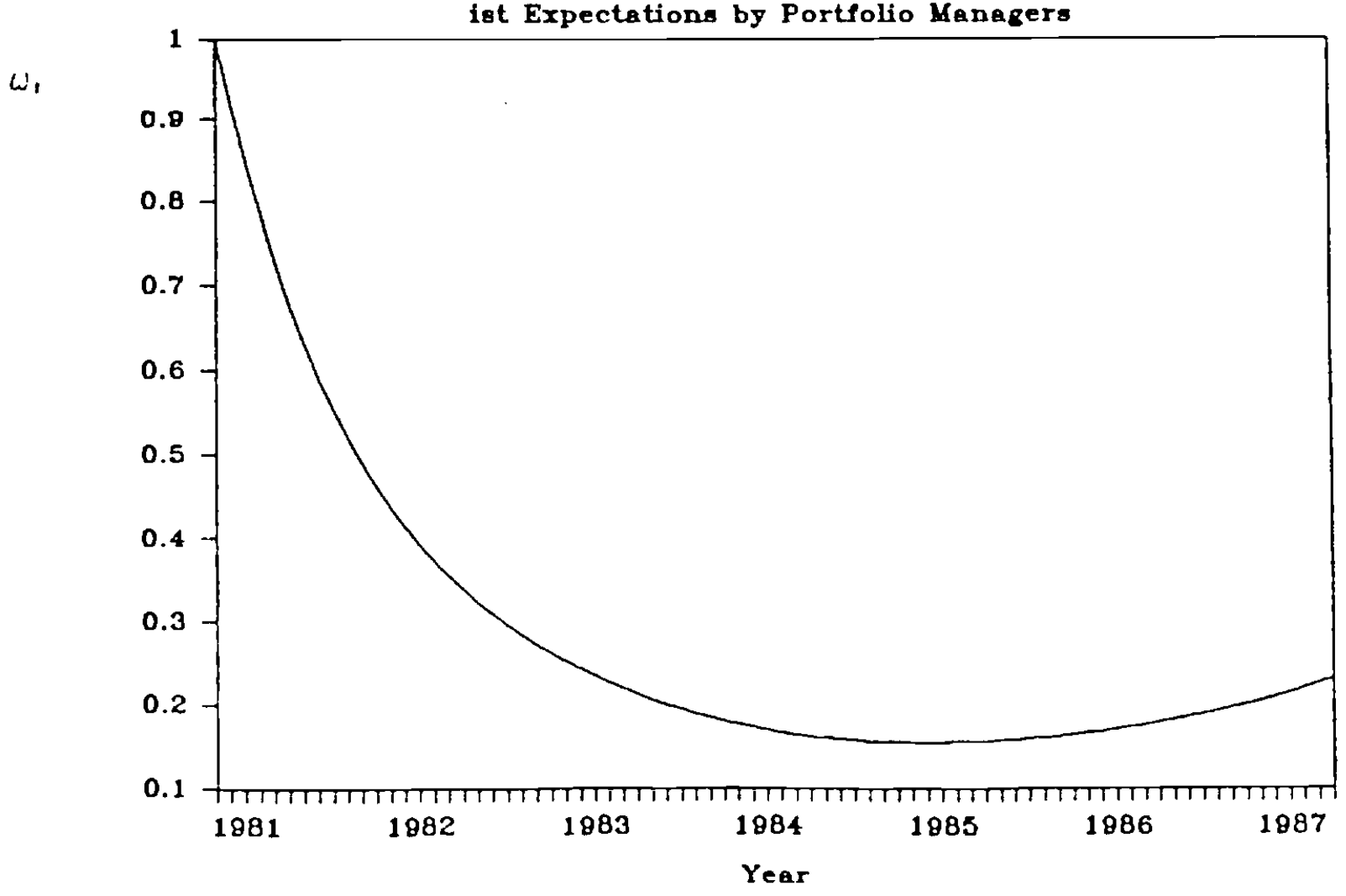



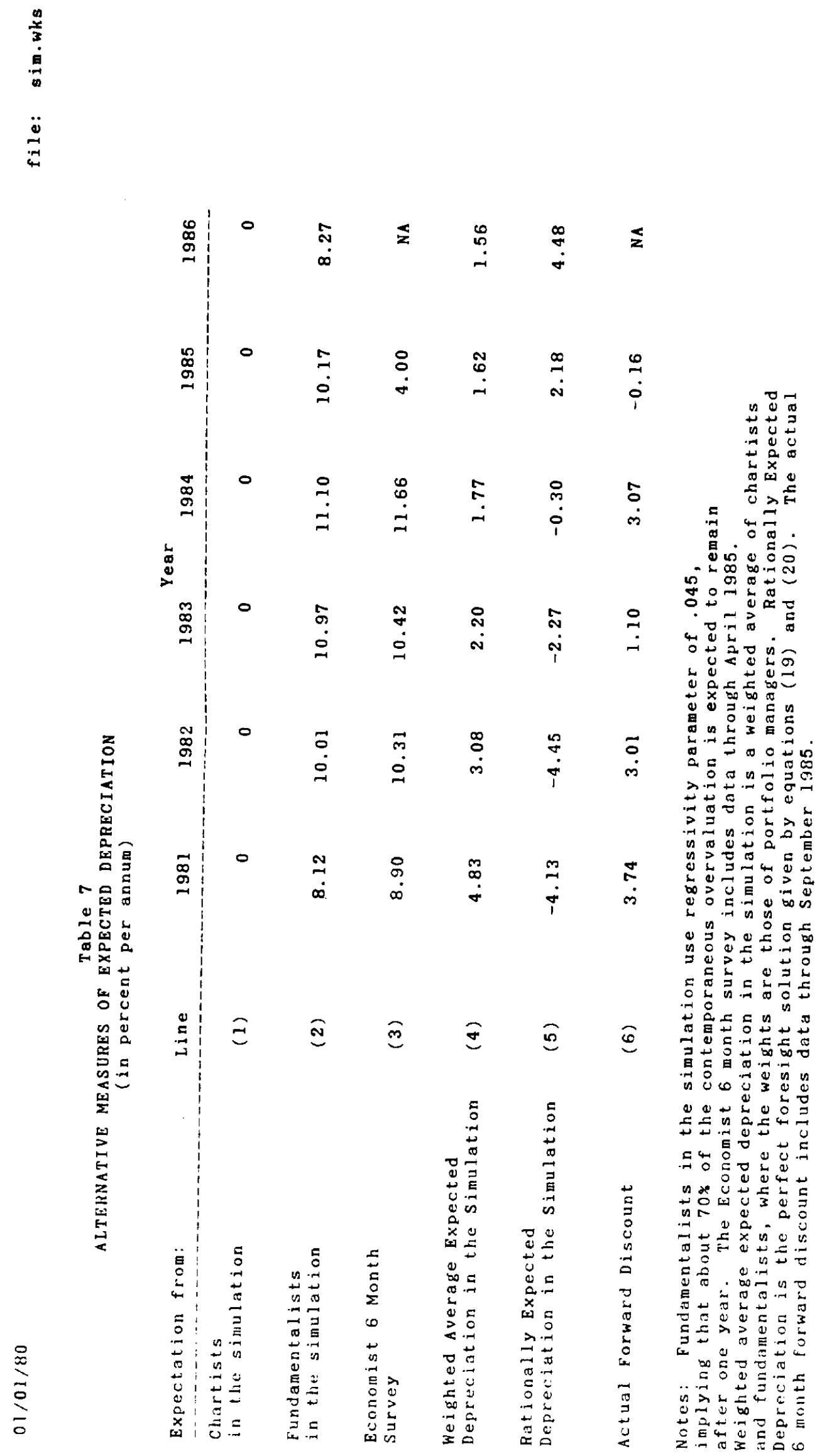


\section{APPENDIX 2}

In this appendix we discuss our choices of important parameters used in the simulations.

The coefficient on expected depreciation in equation (3), c, may be interpreted as the semi-elasticity of demand for domestic assets with respect to alternative (foreign) rates of return. Bilson (1985), for example, interprets $c$ as equal to Cagan's semi-elasticity of money demand. Under the assumptions that the interest elasticity of the demand for money is .15 and that interest rates are approximately 1 percent per month Bilson uses $c=15$. Other possible estimates for $c$ are much higher. An estimate of the semi-elasticity $c$ may be obtained in a mean-variance framework. c then depends on the relative shares of assets in the market portfolio, the variance of the spot rate, and the coefficient of relative risk aversion. Estimates of c (see Frankel (1985), Table 5a) range from 1,800 to 43,800 for various currencies and estimates of portfolio shares. Our choice is somewhere in between Bilson's and Frankel's, $c=25$. Higher values of $c$ tend to exaggerate the rate appreciation of the dollar and also the rate at which $\omega_{t}$ falls (see Table 5 in the text).

The coefficient $\delta$ measures the rate at which portfolio managers "learn:" it is the weight they give to new information about the value of $\omega_{t}$. A crucial assumption of the model is that portfolio managers do put weight on their prior estimate of $\omega_{t}$. If they learn too quickly, the spot rate will be stable and no bubbles will occur. In the simulations in the text, we assume that $\delta=.03$, or that portfolio managers mix the information of the current month's $\omega_{t}$ with data from the past three years.

The parameter $\vartheta$, controls the speed with which the spot rate is expected to regress to $\bar{s}$. In the simulations we chose $\vartheta=.045$, which means fundamentalists expect about 60 percent of the current deviation from $\bar{s}$ to remain after 
1 year. Regression estimates of $v$ from exchange rate survey data in Frankel and Froot (1985) are somewhat smaller (about .02), but in that paper the specification for expected depreciation also included a constant term (i.e. $\left.\Delta s_{t+1}^{f}=\alpha+v(\bar{s}-s(t))\right)$ which was significantly positive (about .01). After including the constant, the surveys predict a somewhat faster return to longrun equilibrium, that only 50 percent of the current overvaluation would remain after one year. The choice of $v=.045$ has the added advantage that the expectations of fundamentalists in the simulation appear very similar to the survey expected depreciation (see Tables 6 and 7, lines two and three). 


\section{References}

Bilson, John, "The Monetary Approach to the Exchange Rate-- Some Empirical Evidence," Staff Papers, International Monetary Fund 25, (March 1978).

" "The Speculative Efficiency Hypothesis," Journal of Business 54 (July 1981), pp. 435-51.

"Macroeconomic Stability and Flexible Exchange Rates," American Economic Review, Papers and Proceedings 75, 2 (May 1985), pp. 62-67.

Blanchard, Olivier and Lawrence Summers, "Perspectives on High World Real Interest Rates," Brookings Papers on Economic Activity 2 (1984), pp. 273324.

Boothe, P., K. Clinton, A. Cote, and D. Longworth, International Asset Substitutability: Theory and Evidence for Canada (Ottawa), Bank of Canada February 1985.

Branson, William H., "Causes of Appreciation and Volatility of the Dollar," Federal Reserve Bank of Kansas City Conference Paper, (August 1985).

Claassen, Emil and Charles Wyplosz, "Capital Controls: Some Principles and the French Experience," Annales de l'INSEE 47-48 (June-December 1982), pp. 237-67.

Council of Economic Advisers, The Economic Report of the President, Washington, D.C., 1984.

Cumby, Robert and Maurice Obstfeld, "International Interest Rate and Price Level Linkages under Flexible Exchange Rates: A Review of Recent Evidence," in J. Bilson and R. Marston, eds., Exchange Rate Theory and Practice, Chicago: University of Chicago Press (1984).

Dooley, Michael and Peter Isard, "Capital Controls, Political Risk and Deviations from Interest-Rate Parity." Journal of Political Economy 88, 2 (April 1980), pp. 370-384.

"The Appreciation of the Dollar: An Analysis of the Safe-Haven Phenomenon," International Monetary Fund, DM/85/20 (April 1985).

Dominguez, Kathryn, "Expectations Formation in the Foreign Exchange Market: New Evidence from Survey Data," Yale University, (January 1986).

Dornbusch, Rudiger, "Expectations and Exchange Rate Dynamics," Journal of Political Economy 84 (December 1976), pp. 1161-76.

"Equilibrium and Disequilibrium Exchange Rates," Zeitschrift fur Wirtschafts und Sozialwissenschaften 102, 6 (1982), pp. 573-99. 
Comment on Loopesko and Shafer, Brookings Papers on Economic Activity 1 (1983), pp. 78-84.

Evans, George, "Speculative Bubbles and the Sterling-Dollar Exchange Rate: A New Test," Stanford University (September 1985). Fama, Eugene, "Forward and Spot Exchange Rates," Journal of Monetary
Economics, 1984.

Figlewski, Stephen, "Market 'Efficiency' in a Market with Heterogeneous Information," Journal of Political Economy, vol. 86, 4, 581-597, 1978.

"Information Diversity and Market Behavior," Journal of Finance, pp. 87-102, March 1982.

Frankel, Jeffrey, "Monetary and Portfolio-Balance Models of Exchange Rate Determination," in J. Bhandari, ed., Economic Interdependence and Flexible Exchange Rates, Cambridge, MA: M.I.T. Press (1983).

The Yen/Dollar Agreement: Liberalizing Japanese Capital Markets, Policy Analyses in International Economics No. 9 (Washington D.C.: Institute for International Economics, 1984).

"The Dazzling Dollar," Brookings Papers on Economic Activity 1 (1985), pp. 199-217.

"Six Possible Meanings of 'Overvaluation:' The 1981-85 Dollar," Princeton Essays in International Finance 15, International Finance Section, Princeton University (1985, forthcoming).

"The Implications of Mean-Variance Optimization for Four Questions in International Macroeconomics," NBER Working Paper No.1617. Journal of International Money and Finance (1986, forthcoming).

Frankel, Jeffrey and Charles Engel, "Do Asset-Demand Functions Optimize Over the Mean and Variance of Real Returns? A Six-Currency Test." Journal of International Economics 17 (1984). pp. 309-23.

Frankel, Jeffrey and Kenneth Froot, "Using Survey Data to Test Some Standard Propositions Regarding Exchange Rate Expectations," NBER Working Paper No. 1672 (August 1985).

Frenkel, Jacob, "A Monetary Approach to the Exchange Rate: Doctrinal Aspects and Empirical Evidence." Scandinavian Journal of Economics 78 (May 1976), pp. 200-24.

"Transaction Costs and Interest Arbitrage: Tranquil versus Turbulent Periods," Journal of Political Economy 85, 6 (December 1977), pp. 1209-26. 
Frenkel, Jacob, and Richard Levich, "Covered Interest Arbitrage: Unexploited Profits?" Journal of Political Economy B3, 2 (April 1975), pp. 325-38.

Friedman, Benjamin, "Implications of the U.S. Net Capital Inflow," How Open is the U.S. Economy?. Conference at the Federal Reserve Bank of St. Louis, October 11-12, 1985.

Friend, Irwin and Marshall Blume. "The Demand for Risky Assets" American Economic Review 65 (December 1975), pp. 900-22.

Froot, Kenneth. "Exchange Rate Survey Data: The Roles of Expectational Errors, the Risk Premium and Measurement Error," University of California, Berkeley (September 1985).

Giavazzi, Francesco and Marco Pagano, "Capital Controls and the European Monetary System," in Capital Controls and Foreign Exchange Legislation, Occasional Paper, Euromobiliare, Milano (June 1985).

Hartman, David, "The International Financial Market and U.S. Interest Rates," Journal of International Money and Finance 3 (April 1984).

Hodrick, Robert and Sanjay Srivastava, "An Investigation of Risk and Return in Forward Foreign Exchange" Journal of International Money and Finance 3 (1984), pp. 5-24.

Ito, Takatoshi, "Capital Controls and Covered Interest Parity," NBER Horking Paper No. 1187 (August 1983).

Kling, Arnold, "Anticipatory Capital Flows and the Behavior of the Dollar," International Finance Discussion Paper No. 261, Federal Reserve Board (August 1985).

Kohlhagen, Steven, "The Behavior of Foreign Exchange Markets-- A critical Survey of the Empirical Literature," N.Y.U. Monograph Series in Finance and Economics (1978).

Kouri, Pentti J.K., "The Exchange Rate and the Balance of Payments in the Short Run and the Long Run: A Monetary Approach," Scandinavian Journal of Economics (1976), pp. 280-304.

Kreicher, Lawrence, "Eurodollar Arbitrage," Federal Reserve Bank of New York Quarterly Review 7, 2 (Summer 1982), pp. 10-12.

Krugman, Paul, "Is the Strong Dollar Sustainable?" Federal Reserve Bank of Kansas City Conference at Jackson Hole (Wyoming, August 21-23, 1985), NBER Working Paper No. litil.

Longworth, David, "Testing the Efficiency of the Canadian-L.S. Exchange Market under the Assumption of no Risk Premium," Journal of Finance 36 (March 1981) pp. 43-49. 
Marris, Stephen, Deficits and the Dollar: The World Economy at Risk, Policy Analyses in International Economics (Washington: Institute for International Economics, 1985).

McCormick, Frank, "Covered Interest Arbitrage: Unexploited Profits? Comment," Journal of Political Economy 1979.

McKinnon, Ronald, "Floating Exchange Rates 1973-74: The Emperor's New Clothes," Carnegie-Rochester Conference Series on Public Policy 3 (1976). pp. 79-114.

Meese, Richard and Kenneth Rogoff, "Empirical Exchange Rate Models of the Seventies: Do They Fit Out of Sample?" Journal of International Economics 14 (February 1983), pp. 3-24.

Mussa, Michael, "The Exchange Rate, the Balance of Payments and Monetary and Fiscal Policy under a Regime of Controlled Floating." Scandinavian Journal of Economics 78 (May 1976), pp. 229-48.

Obstfeld, Maurice, "Floating Exchange Rates: Experience and Prospects," Brookings Papers on Economics Activity 2 (1985).

Otani, Ichiro, "Exchange Rate Instability and Capital Controls: The Japanese Experience 1978-81," in D. Bigman and T. Taya, eds., Exchange Rate and Trade Instability: Causes, Consequences and Remedies, Cambridge, Mass.:

and Siddarth Tiwari, "Capital Controls and Interest Rate Parity: The Japanese Experience 1978-81," Staff Papers, International Monetary Fund (Washington, December 1981).

Rodriguez, Carlos Alfredo, "The Role of Trade Flows in Exchange Rate Determination: A Rational Expectations Approach," Journal of Political Economy 88 (1980), pp. 1148-58.

Shiller, Robert, "Stock Prices and Social Dynamics," Brookings Papers on Economic Activity 2 (1984), pp. 457-510.

Stern, Nicholas, "The Marginal Valuation of Income," in M.J. Artis and A.R. Nobay, eds., Studies in Modern Economic Analysis, Oxford: Basil Blackwell, (1977) pp. 145-76.

Tryon, Ralph, "Testing for Rational Expectations in Foreign Exchange Markets," International Finance Discussion Paper No. 139, Federal Reserve Board,
(1979). 
</ref_section> 